\title{
Organic molecules in the Galactic center ${ }^{\star}$ Hot core chemistry without hot cores
}

\author{
M. A. Requena-Torres ${ }^{1}$, J. Martín-Pintado ${ }^{1}$, A. Rodríguez-Franco ${ }^{1,2}$, S. Martín ${ }^{3}$, \\ N. J. Rodríguez-Fernández ${ }^{4}$, and P. de Vicente ${ }^{5}$
}

1 Departamento de Astrofísica Molecular e Infrarroja, Instituto de Estructura de la Materia-CSIC C Serrano 121, 28006 Madrid, Spain e-mail: requena@damir.iem.csic.es

2 Escuela Universitaria de Óptica, Departamento de Matemática Aplicada (Biomatemática), Universidad Complutense de Madrid, Avenida Arcos de Jalón s/n, 28037 Madrid, Spain

3 Instituto de Radioastronomía Milimétrica Av. Divina Pastora 7, Local 20, 18012 Granada, Spain e-mail: martin@iram.es

${ }^{4}$ Observatoire de Bordeaux, L3AB (UMR 5804), CNRS/Université Bordeaux 1, BP 89, 2 rue de l'Observatoire, 33270 Floirac, France e-mail: nemesio.rodriguez@obs.u-bordeaux1.fr

5 Observatorio Astronómico Nacional, Centro Astronómico de Yebes Apartado 148, 19080 Guadalajara, Spain e-mail: p.devicente@oan.es

Received 13 March 2006 / Accepted 11 April 2006

\begin{abstract}
Aims. We study the origin of large abundances of complex organic molecules in the Galactic center (GC). Methods. We carried out a systematic study of the complex organic molecules $\mathrm{CH}_{3} \mathrm{OH}, \mathrm{C}_{2} \mathrm{H}_{5} \mathrm{OH},\left(\mathrm{CH}_{3}\right)_{2} \mathrm{O}, \mathrm{HCOOCH}, \mathrm{HCOOH}$ $\mathrm{CH}_{3} \mathrm{COOH}, \mathrm{H}_{2} \mathrm{CO}$, and $\mathrm{CS}$ toward $40 \mathrm{GC}$ molecular clouds. Using the LTE approximation, we derived the physical properties of GC molecular clouds and the abundances of the complex molecules. The abundances of complex organic molecules in the GC are compared with those measured in hot cores and hot corinos, in which these complex molecules are also abundant.

Results. The $\mathrm{CH}_{3} \mathrm{OH}$ abundance between clouds varies by nearly two orders of magnitude from $2.4 \times 10^{-8}$ to $1.1 \times 10^{-6}$. The abundance of the other complex organic molecules relative to that of $\mathrm{CH}_{3} \mathrm{OH}$ is basically independent of the $\mathrm{CH}_{3} \mathrm{OH}$ abundance, with variations of only a factor 4-8. We find that both the abundance and the abundance ratios of the complex molecules relative to $\mathrm{CH}_{3} \mathrm{OH}$ in hot cores are similar to those found in the GC clouds. However, hot corinos show different abundance ratios than observed in hot cores and in GC clouds. The rather constant abundance of all the complex molecules relative to $\mathrm{CH}_{3} \mathrm{OH}$ suggests that all complex molecules are ejected from grain mantles by shocks. Frequent $\left(\sim 10^{5}\right.$ years $)$ shocks with velocities $>6 \mathrm{~km} \mathrm{~s}^{-1}$ are required to explain the high abundances in gas phase of complex organic molecules in the GC molecular clouds. The rather uniform abundance ratios in the GC clouds and in Galactic hot cores indicate a similar average composition of grain mantles in both kinds of regions. The Sickle and the Thermal Radio Arches, affected by UV radiation, show different relative abundances in the complex organic molecules due to the differentially photodissociation of these molecules.
\end{abstract}

Key words. astrochemistry - ISM: clouds - ISM: molecules - radio lines: ISM - Galaxy: center

\section{Introduction}

Gas-grain interaction in the interstellar medium (ISM) can have a large impact on its chemistry because of the desorption and/or depletion of molecules onto grains mantles. The gas phase abundance of molecules, which are believed to be efficiently formed on dust grains such as, methanol $\left(\mathrm{CH}_{3} \mathrm{OH}\right)$, ethanol $\left(\mathrm{C}_{2} \mathrm{H}_{5} \mathrm{OH}\right)$, and formaldehyde $\left(\mathrm{H}_{2} \mathrm{CO}\right)$, can be enhanced by orders of magnitude due to the ejection/evaporation of these molecules from grain mantles.

One of the interesting features of the gas-phase chemistry after ejection of these molecules is the fast conversion of these parent molecules into daughter molecules. The relative abundance of dimethyl ether $\left(\left(\mathrm{CH}_{3}\right)_{2} \mathrm{O}\right)$ is expected to change by

* Table 7 is only available in electronic form at the CDS via anonymous ftp to cdsarc.u-strasbg.fr (130.79.128.5) or via http://cdsweb.u-strasbg.fr/cgi-bin/qcat? J/A+A/455/971 three orders of magnitude in a short period of time after $\mathrm{CH}_{3} \mathrm{OH}$ is ejected to gas phase (Millar et al. 1991; Caselli et al. 1993; Charnley et al. 1995; Horn et al. 2004). Basically all models of alcohol-driven chemistry have indicated that $\left(\mathrm{CH}_{3}\right)_{2} \mathrm{O}$ and methyl formate $\left(\mathrm{HCOOCH}_{3}\right)$ will reach their largest abundances $10^{4}-10^{5}$ years after the ejection of $\mathrm{CH}_{3} \mathrm{OH}$ into gas phase. However, Horn et al. (2004) have shown that $\mathrm{HCOOCH}_{3}$ formation in gas phase from $\mathrm{CH}_{3} \mathrm{OH}$ is less efficient than previously considered in the models. This casts some doubts on the gas-phase production of $\mathrm{HCOOCH}_{3}$, and they propose that this molecule is also formed on grain mantles. The gas phase/grain formation of $\left(\mathrm{CH}_{3}\right)_{2} \mathrm{O}$ has been studied by Peeters et al. (2006), showing that the main path to form $\left(\mathrm{CH}_{3}\right)_{2} \mathrm{O}$ is by gas-phase reactions and that its formation on grains is a minor source of the observed abundances. Other organic molecules like formic acid $(\mathrm{HCOOH})$ can be produced in both gas phase and grain mantle chemistry (Liu et al. 2002). 
So far, large abundances of complex molecules have been detected in three different kinds of objects: hot cores associated with massive star formation (Ikeda et al. 2001), hot corinos associated with low-mass star formation (Bottinelli et al. 2006), and the Galactic center (GC) clouds (Martín-Pintado et al. 2001). Their physical properties are very different. While the hot cores and hot corinos are small $(\lesssim 0.1 \mathrm{pc})$, hot $(>100 \mathrm{~K})$, and very dense $\left(\gtrsim 10^{5} \mathrm{~cm}^{-3}\right)$ condensations, the GC molecular clouds show averaged scales of 20-30 pc, kinetic temperatures $\sim 50-200 \mathrm{~K}$, and an averaged density of $\sim 10^{4} \mathrm{~cm}^{-3}$ (Güsten \& Philipp 2004). The molecular gas in the inner region of our Galaxy presents a different chemistry than in the Galactic disk (Martín-Pintado et al. 1997). In the GC, widespread large abundances of grain-processed molecules like $\mathrm{CH}_{3} \mathrm{OH}, \mathrm{C}_{2} \mathrm{H}_{5} \mathrm{OH}$, and silicon monoxide ( $\mathrm{SiO}$ ) are observed (Gottlieb et al. 1979; Minh et al. 1992; Martín-Pintado et al. 1997, 2001; Hüttemeister et al. 1998). It has been proposed that the sputtering of grains and grain mantles produced by widespread shocks with moderated velocities of $\leq 40 \mathrm{~km} \mathrm{~s}^{-1}$ are the responsible of the "rich" chemistry observed in the GC clouds. The origin of the large scale shocks is so far unclear. These shocks could be produced by cloud-cloud collisions associated with the largescale dynamics in the context of a barred potential (Hasegawa et al. 1994; Hüttemeister et al. 1998; Rodríguez-Fernández et al. 2006), by wind-blown bubbles driven by evolved massive stars (Martín-Pintado et al. 1999), or by hydrodynamic (HD) or magneto hydrodynamic turbulence (MHD) (Morris \& Serabyn 1996). Since the formation of some complex organic molecules is believed to proceed in gas phase after the passage of the shocks and their abundances rapidly evolve, one could use the abundances of these molecules to gain insight into the chemistry of complex molecules in the ISM and to constrain the age of shocks in the GC (Martín-Pintado et al. 2001).

Following these ideas we made a systematic study of 40 molecular clouds in the GC region, between Sgr B2 and $\mathrm{Sgr} \mathrm{C}$, in complex molecules believed to be formed on grains like $\mathrm{CH}_{3} \mathrm{OH}, \mathrm{C}_{2} \mathrm{H}_{5} \mathrm{OH}$, and $\mathrm{HCOOCH}_{3}$, in gas phase from $\mathrm{CH}_{3} \mathrm{OH}$ like $\left(\mathrm{CH}_{3}\right)_{2} \mathrm{O}$ and in gas phase and/or grains like $\mathrm{HCOOH}$ and $\mathrm{H}_{2} \mathrm{CO}$. We also searched for the less abundant isomer of $\mathrm{HCOOCH}_{3}$, the acetic acid $\left(\mathrm{CH}_{3} \mathrm{COOH}\right)$. As tracers of the total column density of the molecular gas, we observed molecules like $\mathrm{C}^{18} \mathrm{O},{ }^{13} \mathrm{CO}$, and $\mathrm{CS}$. Our systematic study shows that all the complex organic molecules present similar relative abundances with respect to $\mathrm{CH}_{3} \mathrm{OH}$, except for the regions where photodissociation could be important. Furthermore, the abundance and abundance ratios of these complex molecules in the GC are similar to those observed in hot cores, while hot corino abundances seem to have similar ratios for different objects. Our results suggest that all complex organic molecules have been ejected from grain mantles and that their abundances represent, in first approximation, the grain mantle composition.

\section{Observations and results}

The observations of all transitions of the complex organic molecules shown in Table 1 were carried out with the IRAM 30$\mathrm{m}$ radio telescope at Pico Veleta (Spain). The data were obtained in different seasons between 1996 and 2003. The half-power beam width of the telescope was $24^{\prime \prime}, 17^{\prime \prime}$, and $12^{\prime \prime}$ for the 3 , 2 , and $1.3 \mathrm{~mm}$ bands. The receivers, equipped with SIS mixers, were tuned to single sideband with image rejections $\gtrsim 10 \mathrm{~dB}$. The typical system temperatures were 300,500 , and $900 \mathrm{~K}$ for the 3,2 , and $1.3 \mathrm{~mm}$ lines, respectively. We used two filterbanks of $256 \times 1 \mathrm{MHz}$ and one of $512 \times 1 \mathrm{MHz}$ as spectrometers. The
Table 1. Molecular line parameters.

\begin{tabular}{|c|c|c|c|c|}
\hline Molecule & Transition & $\begin{array}{r}\text { Frequency } \\
(\mathrm{MHz})\end{array}$ & $\begin{array}{r}E_{\mathrm{u}} / \kappa \\
(\mathrm{K})\end{array}$ & $\mu_{x}^{2} S$ \\
\hline \multirow[t]{6}{*}{$\mathrm{CH}_{3} \mathrm{OH} \ldots \ldots .}$. & $3_{0} \rightarrow 2_{0} \mathrm{E}$ & 145093.75 & 27.06 & 2.38 \\
\hline & $3_{-1} \rightarrow 2_{-1} \mathrm{E}$ & 145097.47 & 19.52 & 2.11 \\
\hline & $3_{0} \rightarrow 2_{0} \mathrm{~A}+$ & 145103.23 & 13.94 & 2.38 \\
\hline & $5_{0} \rightarrow 4_{0} \mathrm{E}$ & 241700.22 & 47.95 & 3.91 \\
\hline & $5_{-1} \rightarrow 4_{-1} \mathrm{E}$ & 241767.22 & 40.41 & 3.75 \\
\hline & $5_{0} \rightarrow 4_{0} \mathrm{~A}+$ & 241791.43 & 34.83 & 4.94 \\
\hline \multirow[t]{3}{*}{${ }^{13} \mathrm{CH}_{3} \mathrm{OH} \ldots$} & $3_{03} \rightarrow 2_{02} \mathrm{E}$ & 141595.48 & 26.71 & 2.43 \\
\hline & $3_{-13} \rightarrow 2_{-12} \mathrm{E}$ & 141597.06 & 19.21 & 2.16 \\
\hline & $3_{03} \rightarrow 2_{02} \mathrm{~A}+$ & 141602.53 & 13.60 & 2.43 \\
\hline \multirow[t]{3}{*}{$\mathrm{C}_{2} \mathrm{H}_{5} \mathrm{OH} \ldots \ldots$} & $4_{14} \rightarrow 3_{03}$ & 90117.61 & 9.36 & 5.35 \\
\hline & $7_{07} \rightarrow 6_{16}$ & 104487.26 & 23.26 & 8.61 \\
\hline & $9_{09} \rightarrow 8_{18}$ & 142285.05 & 37.17 & 12.66 \\
\hline \multirow[t]{7}{*}{$\mathrm{HCOOCH}_{3} .}$. & $7_{25} \rightarrow 6_{24} \mathrm{E}$ & 90145.69 & 19.69 & 17.00 \\
\hline & $7_{25} \rightarrow 6_{24} \mathrm{~A}$ & 90156.48 & 19.67 & 17.00 \\
\hline & $8_{08} \rightarrow 7_{07} \mathrm{E}$ & 90227.61 & 20.09 & 20.99 \\
\hline & $8_{08} \rightarrow 7_{07} \mathrm{~A}$ & 90229.63 & 20.07 & 20.99 \\
\hline & $9_{45} \rightarrow 8_{44} \mathrm{E}$ & 111408.48 & 37.27 & 19.13 \\
\hline & $9_{18} \rightarrow 8_{17} \mathrm{E}$ & 111674.10 & 28.15 & 23.12 \\
\hline & $9_{18} \rightarrow 8_{17} \mathrm{~A}$ & 111682.19 & 28.13 & 23.12 \\
\hline \multirow[t]{2}{*}{$(\mathrm{CH} 3)_{2} \mathrm{O}^{a} \ldots}$. & $7_{26} \rightarrow 7_{17}$ & 104703.30 & 31.07 & 5.43 \\
\hline & $7_{07} \rightarrow 6_{16}$ & 111783.01 & 25.26 & 6.80 \\
\hline \multirow[t]{2}{*}{ HCOOH ........ } & $4_{22} \rightarrow 3_{21}$ & 90164.25 & 23.53 & 5.78 \\
\hline & $5_{05} \rightarrow 4_{04}$ & 111746.79 & 16.13 & 9.65 \\
\hline \multirow[t]{4}{*}{$\mathrm{CH}_{3} \mathrm{COOH} .}$. & $8_{* 8} \rightarrow 7_{* 7} \mathrm{~A}$ & 90246.25 & 20.30 & 43.20 \\
\hline & $8_{* 8} \rightarrow 7_{* 7} \mathrm{E}$ & 90203.44 & 20.30 & 43.20 \\
\hline & $10_{* 10} \rightarrow 9_{* 9} \mathrm{~A}$ & 111548.53 & 30.50 & 54.80 \\
\hline & $10_{* 10} \rightarrow 9_{* 9} \mathrm{E}$ & 111507.27 & 30.50 & 54.80 \\
\hline \multirow[t]{2}{*}{ CS ….................. } & $3 \rightarrow 2$ & 146969.03 & 14.12 & 11.56 \\
\hline & $5 \rightarrow 4$ & 244936.64 & 35.28 & 19.84 \\
\hline \multirow[t]{2}{*}{$\mathrm{C}^{18} \mathrm{O} \ldots \ldots .}$. & $1 \rightarrow 0$ & 109782.17 & 5.28 & 0.01 \\
\hline & $2 \rightarrow 1$ & 219560.35 & 15.82 & 0.02 \\
\hline${ }^{13} \mathrm{CO} \ldots \ldots \ldots$. & $1 \rightarrow 0$ & 110201.35 & 5.30 & 0.01 \\
\hline $\mathrm{H}_{2}^{13} \mathrm{CO} \ldots \ldots$. & $2_{02} \rightarrow 1_{01}$ & 141983.74 & 7.11 & 10.87 \\
\hline
\end{tabular}

${ }^{a} \mathrm{EE}, \mathrm{AA}, \mathrm{EA}$, and AE substates blended. Only the most intense transition is given.

velocity resolutions provided by the filter banks were 3,2 , and $1.3 \mathrm{~km} \mathrm{~s}^{-1}$ for the 3,2 , and $1.3 \mathrm{~mm}$ bands, respectively. Spectra were calibrated using the standard dual load system. We used the antenna temperature scale $\left(T_{\mathrm{A}}^{*}\right)$ for the line intensities because the emission is rather extended and completely fills the beam.

Figure 1 shows the location of the sources we observed superimposed on the large-scale $\mathrm{SiO}$ map of the GC by MartínPintado et al. (1997). The sources were selected from the SiO maps of Martín-Pintado et al. (1997). Some of these sources had already been observed in $\mathrm{C}_{2} \mathrm{H}_{5} \mathrm{OH}$ by Martín-Pintado et al. (2001). We also included some clouds in Sgr C, the Thermal Radio Arches (TRA) (Serabyn \& Güsten 1987), and the Sickle (Serabyn \& Güsten 1991), where the $\mathrm{C}_{2} \mathrm{H}_{5} \mathrm{OH}$ emission was not detected by Martín-Pintado et al. (2001). The selected molecular clouds are spread over the region between Sgr C and Sgr B2. The positions of the sources are given in galactic and equatorial coordinates in Table 2. The nomenclature used to designate them is similar to that of Martín-Pintado et al. (2001): MC stands for Molecular Cloud followed by a $\mathrm{G}$ and the galactic coordinates, as recommended by the IAU. We grouped the sources in different regions as shown in Fig. 1 and Table 2.

Figures 2 and 3 show samples of line profiles for all observed molecules toward selected sources. Only for some sources like MC G-0.02-0.07 we did observe all the molecular lines. The line profiles of molecules such as $\mathrm{CH}_{3} \mathrm{OH}$ are different from 


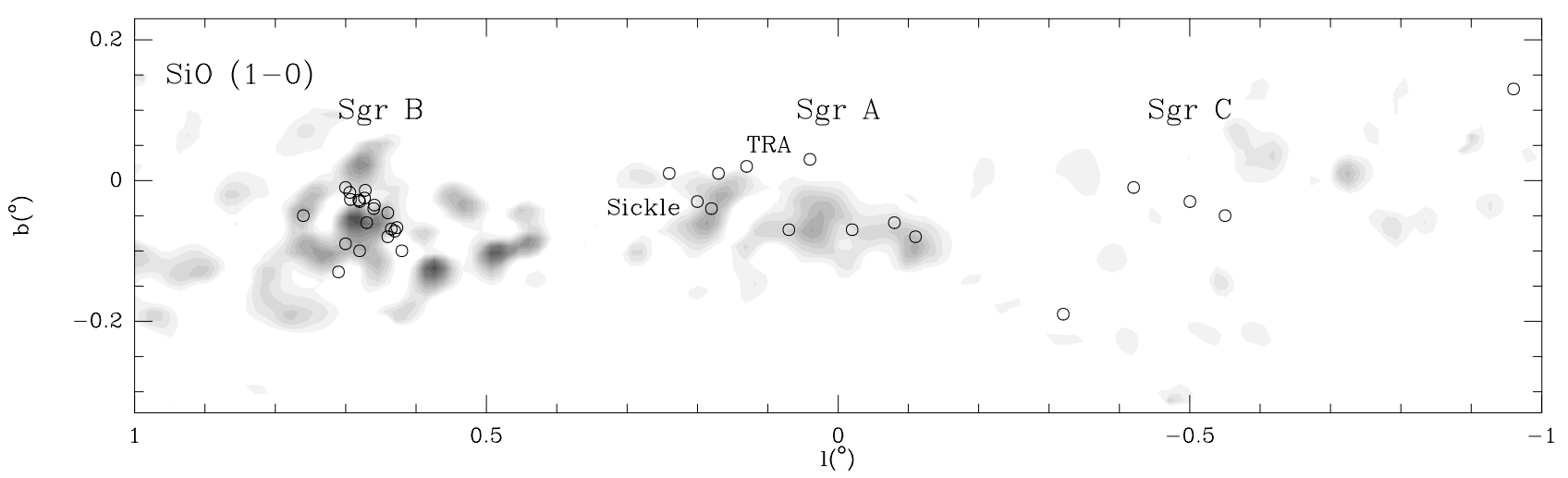

Fig. 1. Position of the observed sources superimposed on the $\mathrm{SiO} J=1 \rightarrow 0$ maps from the GC region by (Martín-Pintado et al. 1997).

Table 2. Source position.

\begin{tabular}{|c|c|c|c|c|c|}
\hline Source & $l\left(^{\circ}\right)$ & $b\left(^{\circ}\right)$ & $\alpha(\mathrm{B} 1950)$ & $\delta(\mathrm{B} 1950)$ & Region \\
\hline MC G-0.96+0.13 & -0.96 & +0.13 & $17^{\mathrm{h}} 39^{\mathrm{m}} 36^{\mathrm{s}} 6$ & $-29^{\circ} 39^{\prime} 47^{\prime \prime}$ & Sgr C \\
\hline MC G-0.55-0.05 & -0.55 & -0.05 & $17^{\mathrm{h}} 41^{\mathrm{m}} 20^{\mathrm{s}} 0$ & $-29^{\circ} 24^{\prime} 30^{\prime \prime}$ & Sgr C \\
\hline MC G-0.50-0.03 & -0.50 & -0.03 & $17^{\mathrm{h}} 41^{\mathrm{m}} 21^{\mathrm{s}} 2$ & $-29^{\circ} 21^{\prime} 26^{\prime \prime}$ & Sgr C \\
\hline MC G-0.42-0.01 & -0.42 & -0.01 & $17^{\mathrm{h}} 41^{\mathrm{m}} 24^{\mathrm{s}} 1$ & $-29^{\circ} 15^{\prime} 51^{\prime \prime}$ & Sgr C \\
\hline MC G-0.32-0.19 & -0.32 & -0.19 & $17^{\mathrm{h}} 42^{\mathrm{m}} 24^{\mathrm{s}} 7$ & $-29^{\circ} 17^{\prime} 20^{\prime \prime}$ & Sgr C \\
\hline MC G-0.11-0.08 & -0.11 & -0.08 & $17^{\mathrm{h}} 42^{\mathrm{m}} 28^{\mathrm{s}} 0$ & $-29^{\circ} 02^{\prime} 55^{\prime \prime}$ & Sgr A \\
\hline MC G-0.08-0.06 & -0.08 & -0.06 & $17^{\mathrm{h}} 42^{\mathrm{m}} 30^{\mathrm{s}} 0$ & $-29^{\circ} 00^{\prime} 58^{\prime \prime}$ & Sgr A \\
\hline MC G-0.02-0.07 & -0.02 & -0.07 & $17^{\mathrm{h}} 42^{\mathrm{m}} 40^{\mathrm{s}} 0$ & $-28^{\circ} 58^{\prime} 00^{\prime \prime}$ & Sgr A \\
\hline $\mathrm{MC} \mathrm{G}+0.04+0.03$ & +0.04 & +0.03 & $17^{\mathrm{h}} 42^{\mathrm{m}} 26^{\mathrm{s}} 2$ & $-28^{\circ} 51^{\prime} 45^{\prime \prime}$ & TRA \\
\hline $\mathrm{MC} \mathrm{G}+0.07-0.07$ & +0.07 & -0.07 & $17^{\mathrm{h}} 42^{\mathrm{m}} 54^{\mathrm{s}} 2$ & $-28^{\circ} 53^{\prime} 30^{\prime \prime}$ & TRA \\
\hline $\mathrm{MC} \mathrm{G}+0.13+0.02$ & +0.13 & +0.02 & $17^{\mathrm{h}} 42^{\mathrm{m}} 41^{\mathrm{s}} 4$ & $-28^{\circ} 47^{\prime} 35^{\prime \prime}$ & TRA \\
\hline $\mathrm{MC} \mathrm{G}+0.17+0.01$ & +0.17 & +0.01 & $17^{\mathrm{h}} 42^{\mathrm{m}} 50^{\mathrm{s}} 0$ & $-28^{\circ} 45^{\prime} 50^{\prime \prime}$ & TRA \\
\hline $\mathrm{MC} \mathrm{G+0.18-0.04}$ & +0.18 & -0.04 & $17^{\mathrm{h}} 43^{\mathrm{m}} 01^{\mathrm{s}} 0$ & $-28^{\circ} 47^{\prime} 15^{\prime \prime}$ & Sickle \\
\hline $\mathrm{MC} \mathrm{G}+0.20-0.03$ & +0.20 & -0.03 & $17^{\mathrm{h}} 43^{\mathrm{m}} 03^{\mathrm{s}} 6$ & $-28^{\circ} 45^{\prime} 42^{\prime \prime}$ & Sickle \\
\hline $\mathrm{MC} \mathrm{G}+0.24+0.01$ & +0.24 & +0.01 & $17^{\mathrm{h}} 42^{\mathrm{m}} 59^{\mathrm{s}} 6$ & $-28^{\circ} 42^{\prime} 35^{\prime \prime}$ & Sickle \\
\hline $\mathrm{MC} \mathrm{G}+0.62-0.10$ & +0.62 & -0.10 & $17^{\mathrm{h}} 44^{\mathrm{m}} 18^{\mathrm{s}} 0$ & $-28^{\circ} 26^{\prime} 30^{\prime \prime}$ & Sgr B2_a \\
\hline $\mathrm{MC} \mathrm{G}+0.64-0.08$ & +0.64 & -0.08 & $17^{\mathrm{h}} 44^{\mathrm{m}} 17^{\mathrm{s}} 5$ & $-28^{\circ} 24^{\prime} 30^{\prime \prime}$ & Sgr B2_a \\
\hline $\mathrm{MC} \mathrm{G}+0.67-0.06$ & +0.67 & -0.06 & $17^{\mathrm{h}} 44^{\mathrm{m}} 18^{\mathrm{s}} 0$ & $-28^{\circ} 22^{\prime} 30^{\prime \prime}$ & Sgr B2_a \\
\hline $\mathrm{MC} \mathrm{G}+0.68-0.10$ & +0.68 & -0.10 & $17^{\mathrm{h}} 44^{\mathrm{m}} 27^{\mathrm{s}} 2$ & $-28^{\circ} 23^{\prime} 20^{\prime \prime}$ & Sgr B2_a \\
\hline $\mathrm{MC} \mathrm{G}+0.70-0.01$ & +0.70 & -0.01 & $17^{\mathrm{h}} 44^{\mathrm{m}} 10^{\mathrm{s}} 0$ & $-28^{\circ} 19^{\prime} 30^{\prime \prime}$ & Sgr B2_a \\
\hline $\mathrm{MC} \mathrm{G}+0.70-0.09$ & +0.70 & -0.09 & $17^{\mathrm{h}} 44^{\mathrm{m}} 27^{\mathrm{s}} 2$ & $-28^{\circ} 22^{\prime} 05^{\prime \prime}$ & Sgr B2_a \\
\hline$+0.71-0.13$ & +0.71 & -0 & $17^{\mathrm{h}} 44^{\mathrm{m}} 38^{\mathrm{s}} 4$ & $-28^{\circ} 22^{\prime} 25^{\prime \prime}$ & Sgr B2_a \\
\hline $\mathrm{MC} \mathrm{G}$ & +0.7 & -0 & $17^{\mathrm{h}} 44^{\mathrm{m}} 27^{\mathrm{s}} 2$ & $-28^{\circ} 17^{\prime} 35^{\prime \prime}$ & Sgr B2_a \\
\hline SGR $\mathrm{I}$ & +0 & & ${ }^{m} 10^{s} 6$ & $1^{\prime} 17^{\prime \prime}$ & Hot Core \\
\hline SGR B & +0.66 & -0.04 & ${ }^{\mathrm{m}} 10^{\mathrm{s}} 6$ & $-28^{\circ} 22^{\prime} 05^{\prime \prime}$ & Hot Core \\
\hline $\mathrm{MC} \mathrm{G}+0.694-0.017$ & +0.694 & -0.017 & $17^{\mathrm{h}} 44^{\mathrm{m}} 10^{\mathrm{s}} 0$ & $-28^{\circ} 20^{\prime} 05^{\prime \prime}$ & Sgr B2 \\
\hline $\mathrm{MC} \mathrm{G}+0.693-0.027$ & +0.693 & -0.027 & $17^{\mathrm{h}} 44^{\mathrm{m}} 12^{\mathrm{s}} 1$ & $-28^{\circ} 20^{\prime} 25^{\prime \prime}$ & Sgr B2 \\
\hline $\mathrm{MC} \mathrm{G}+0.627-0.067$ & +0.627 & -0.067 & $17^{\mathrm{h}} 44^{\mathrm{m}} 12^{\mathrm{s}} 1$ & $-28^{\circ} 25^{\prime} 05^{\prime \prime}$ & Sgr B2 \\
\hline $\mathrm{MC} \mathrm{G}+0.630-0.072$ & +0.630 & -0.072 & $17^{\mathrm{h}} 44^{\mathrm{m}} 13^{\mathrm{s}} 6$ & $-28^{\circ} 25^{\prime} 05^{\prime \prime}$ & Sgr B2 \\
\hline $\mathrm{MC} \mathrm{G}+0.672-0.014$ & +0.672 & -0.014 & $17^{\mathrm{h}} 44^{\mathrm{m}} 06^{\mathrm{s}} 1$ & $-28^{\circ} 21^{\prime} 05^{\prime \prime}$ & Sgr B2 \\
\hline $\mathrm{MC} \mathrm{G}+0.640-0.046$ & +0.640 & -0.046 & $17^{\mathrm{h}} 44^{\mathrm{m}} 09^{\mathrm{s}} 1$ & $-28^{\circ} 23^{\prime} 45^{\prime \prime}$ & Sgr B2 \\
\hline $\mathrm{MC} \mathrm{G}+0.635-0.069$ & +0.635 & -0.069 & $17^{\mathrm{h}} 44^{\mathrm{m}} 13^{\mathrm{s}} 6$ & $-28^{\circ} 24^{\prime} 45^{\prime \prime}$ & Sgr B2 \\
\hline $\mathrm{MC} \mathrm{G}+0.659-0.035$ & +0.659 & -0.035 & $17^{\mathrm{h}} 44^{\mathrm{m}} 09^{\mathrm{s}} 1$ & $-28^{\circ} 22^{\prime} 25^{\prime \prime}$ & Sgr B2 \\
\hline $\mathrm{MC} \mathrm{G}+0.681-0.028$ & +0.681 & -0.028 & $17^{\mathrm{h}} 44^{\mathrm{m}} 10^{\mathrm{s}} 6$ & $-28^{\circ} 21^{\prime} 05^{\prime \prime}$ & Sgr B2 \\
\hline $\mathrm{MC} \mathrm{G}+0.673-0.025$ & +0.673 & -0.025 & $17^{\mathrm{h}} 44^{\mathrm{m}} 09^{\mathrm{s}} 1$ & $-28^{\circ} 21^{\prime} 25^{\prime \prime}$ & Sgr B2 \\
\hline
\end{tabular}

Note. Galactic and equatorial coordinates of the selected sources. Nomenclature, as recommended by the IAU: MC followed by a G and the galactic coordinates, where MC stands for Galactic center molecular cloud. We have grouped the sources by regions: sources around Sgr C, Sgr A, the TRA, the Sickle, Sgr B2 (_a is to difference two observation sessions), and the hot cores. Not all sources in the TRA or in the Sickle are affected by the same physical conditions.

those of the $\mathrm{CO}$ isotopomers and $\mathrm{CS}$ due to the blending of several transitions. The complex organic molecules were only detected in some of the velocity components observed in $\mathrm{C}^{18} \mathrm{O}$, ${ }^{13} \mathrm{CO}$, and CS. A good example of this difference in line profiles is shown in Figs. 2 and 3 for the source MC G+0.76-0.05 where $\mathrm{C}^{18} \mathrm{O},{ }^{13} \mathrm{CO}$, and $\mathrm{CS}$ show three or more velocity components, but $\mathrm{C}_{2} \mathrm{H}_{5} \mathrm{OH}$ only shows one. Each velocity component has been treated as an independent molecular cloud. Multiple velocity components are also found toward $\mathrm{MC} \mathrm{G}+0.13+0.02$,

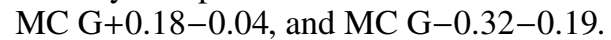



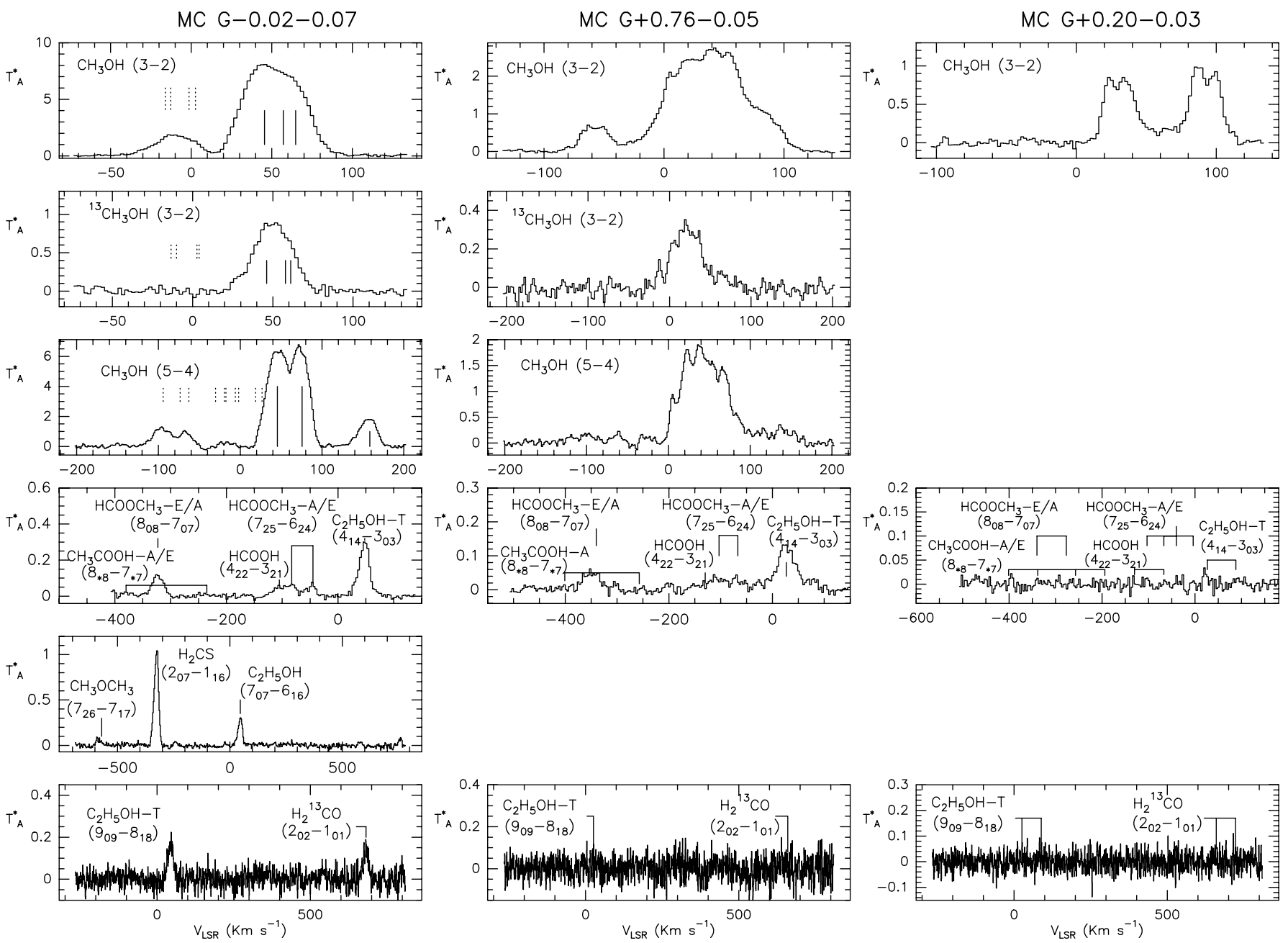

Fig. 2. Observed line profiles toward the sources MC G-0.02-0.07, MC G+0.76-0.05, and MC G+0.20-0.03. Line intensities are expressed in antenna temperature $(\mathrm{K})$, and velocities refer to LSR $\left(\mathrm{km} \mathrm{s}^{-1}\right)$. The $\mathrm{CH}_{3} \mathrm{OH}$ profiles are composed of several overlapped transitions arising from levels with different energies; in the MC G-0.02-0.07 source, we show the transitions with highest intensities as vertical solid lines and the transitions with lowest intensities as dotted lines. These transitions are: for $\mathrm{CH}_{3} \mathrm{OH} J=3 \rightarrow 2$, from left to right, $3_{2} \rightarrow 22_{2} \mathrm{~A}, 3_{1} \rightarrow 2{ }_{1} \mathrm{E}$, $3_{-2} \rightarrow 2_{-2} \mathrm{E}, 3_{2} \rightarrow 22_{2} \mathrm{E}, 3_{2} \rightarrow 2_{2} \mathrm{~A}-, 3_{0} \rightarrow 2_{0} \mathrm{~A}+, 3_{-1} \rightarrow 2_{-1} \mathrm{E}$, and $3_{0} \rightarrow 2_{0} \mathrm{E}$. For the ${ }^{13} \mathrm{CH}_{3} \mathrm{OH} J=3 \rightarrow 2$, from left to right, $3_{21} \rightarrow 22_{20} \mathrm{~A}+$, $3_{12} \rightarrow 2_{11} \mathrm{E}, 3_{21} \rightarrow 2_{21} \mathrm{E}, 3_{-22} \rightarrow 2_{-21} \mathrm{E}, 3_{22} \rightarrow 2_{21} \mathrm{~A}-, 3_{03} \rightarrow 2_{02} \mathrm{~A}+3_{-13} \rightarrow 2_{-12} \mathrm{E}$, and $3_{03} \rightarrow 2_{02} \mathrm{E}$. For the $\mathrm{CH}_{3} \mathrm{OH} J=5 \rightarrow 4$ from left to right; $5_{2} \rightarrow 4_{2} \mathrm{E}, 5_{-2} \rightarrow 4_{-2} \mathrm{E}, 5_{2} \rightarrow 4_{2} \mathrm{~A}+, 5_{1} \rightarrow 4_{1} \mathrm{E}, 5_{-3} \rightarrow 4_{-3} \mathrm{E}, 5_{3} \rightarrow 4_{3} \mathrm{E}, 5_{2} \rightarrow 4_{2} \mathrm{~A}-, 5_{3} \rightarrow 4_{3} \mathrm{~A}-, 5_{3} \rightarrow 4_{3} \mathrm{~A}+, 5_{4} \rightarrow 4_{4} \mathrm{E}, 5_{-4} \rightarrow 4_{-4} \mathrm{E}$ $5_{4} \rightarrow 4_{4} \mathrm{~A}-, 5_{4} \rightarrow 4_{4} \mathrm{~A}, 5_{0} \rightarrow 4_{0} \mathrm{E}, 5_{-1} \rightarrow 4_{-1} \mathrm{E}$, and $5_{0} \rightarrow 4_{0} \mathrm{E}$. All these transitions have been used for the multi-Gaussian fit. The spectrum toward $\mathrm{MC} \mathrm{G}+0.20-0.03$ shows two velocity components.

\section{Analysis of the data}

To derive the physical and chemical properties of the selected molecular clouds, we fitted Gaussian profiles to all detected molecular lines for each velocity component. The observed spectra of some organic molecules are more complex than a single Gaussian profile because of the overlap of several transitions due to the large linewidths observed toward the GC clouds. To account for the overlap, we used the following constrains for the Gaussian fitting depending on the observed transitions:

- For molecules without internal rotation, like $\mathrm{CS}, \mathrm{C}^{18} \mathrm{O}$, ${ }^{13} \mathrm{CO}, \mathrm{HCOOH}$, and $\mathrm{H}_{2}^{13} \mathrm{CO}$, and for molecules with internal rotation when the transitions are sufficiently separated, like those of $\mathrm{C}_{2} \mathrm{H}_{5} \mathrm{OH}$ and some of the $\mathrm{HCOOCH}_{3}$ lines, simple Gaussian profiles were fitted to each transition for every velocity component. As mentioned before, the $\mathrm{CS}, \mathrm{C}^{18} \mathrm{O}$, and ${ }^{13} \mathrm{CO}$ profiles generally show more velocity components than those observed in the complex organic molecules. For this work we only fitted the components in the velocity range where at least one organic molecule was detected. In the case where the velocity components overlapped we calculated the integrated intensity of $\mathrm{CS}, \mathrm{C}^{18} \mathrm{O}$, and ${ }^{13} \mathrm{CO}$ in the velocity range where the complex organic molecules show the emission.

- The $\mathrm{CH}_{3} \mathrm{OH}$ and ${ }^{13} \mathrm{CH}_{3} \mathrm{OH}$ profiles are composed of several overlapped transitions arising from levels at different energies. In this case, we fitted the blended transitions with multi-Gaussian profiles forced to have the same linewidth and velocity separations corresponding to the rest frequencies of the transitions. We also forced the relative intensities derived from the spectroscopic parameters (Tables 1 and 3), assuming the same rotational temperature for all the transitions. In addition to the radial velocity and linewidth, we also fitted the rotational temperature and the optical depths that match the observed profiles. In this case, the antenna temperatures were obtained from $\left(T_{\text {rot }}-T_{\mathrm{bg}}\right)\left(1-\mathrm{e}^{-\tau}\right)$. We used the optically thin emission from ${ }^{13} \mathrm{CH}_{3} \mathrm{OH}$ transitions to test the optical depths and the antenna temperatures 

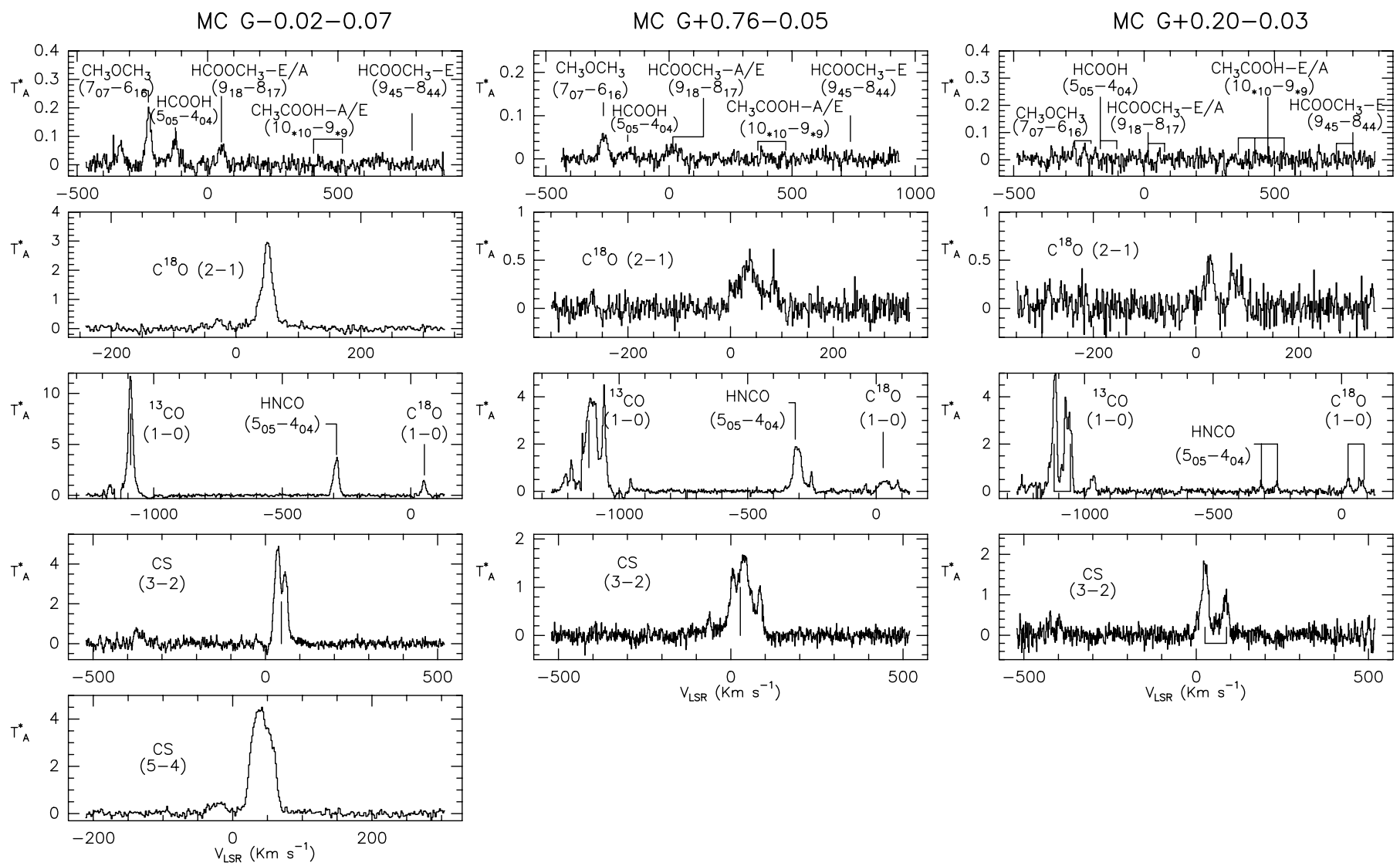

Fig. 3. Same as Fig. 2. The ${ }^{13} \mathrm{CO}, \mathrm{C}^{18} \mathrm{O}$, and $\mathrm{CS}$ profiles show wider lines than those of the complex organic molecules in Fig. 2.

obtained from the $\mathrm{CH}_{3} \mathrm{OH}$ fits. The optical depths derived from the $\mathrm{CH}_{3} \mathrm{OH}$ lines are in good agreement with those obtained from the $\left[\mathrm{CH}_{3} \mathrm{OH} /{ }^{13} \mathrm{CH}_{3} \mathrm{OH}\right]$ line-intensity ratios, assuming a ${ }^{12} \mathrm{C} /{ }^{13} \mathrm{C}$ ratio of 20 (Wilson \& Rood 1994). For the ${ }^{13} \mathrm{CH}_{3} \mathrm{OH}$, and in some cases for the $\mathrm{CH}_{3} \mathrm{OH}$ lines, only the transitions with the largest intensities were fitted. In the case of the $\mathrm{CH}_{3} \mathrm{OH} 5_{0} \rightarrow 4_{0} E$ transition, a simple Gaussian fit was made since this line is not overlapped with any other transition.

- Due to its internal rotation, the $\left(\mathrm{CH}_{3}\right)_{2} \mathrm{O}$ rotational levels are split into four substates with similar Einstein coefficients but different intensities due to the nuclear spin degeneracy. These substates are called AA, EE, EA, and AE. Since the four substates are blended, we measured the integrated intensity of the four substates and then summed all the spin weights of each substate to derive the $\left(\mathrm{CH}_{3}\right)_{2} \mathrm{O}$ column densities.

- To obtain the upper limits to the column densities of undetected transitions like those of $\mathrm{CH}_{3} \mathrm{COOH}$, we used the $3 \sigma$ level for the integrated intensities.

Derived parameters from the Gaussian fits (peak intensity, integrated intensity, radial velocity and linewidth) for all transitions in each source are shown electronically in Table 7, available at the CDS.

The linewidths of the complex organic molecules in our sources are $\sim 15 \mathrm{~km} \mathrm{~s}^{-1}$, typical in the GC region. Radial velocities of the different sources range from $-93 \mathrm{~km} \mathrm{~s}^{-1}$ to $140 \mathrm{~km} \mathrm{~s}^{-1}$.

\section{Derived parameters}

\subsection{Column densities, excitation temperatures, and densities}

Molecular column densities were derived by assuming optically thin emission and the local thermodynamic equilibrium (LTE) approximation. In the case of optically thick lines like those of $\mathrm{CH}_{3} \mathrm{OH}$, the optically thin isotopic substitution was used. Under these conditions, the total column density, $N$, of a molecule is given by:

$N=\frac{N_{\mathrm{u}}}{g_{\mathrm{u}} g_{\mathrm{i}}} Q \mathrm{e}^{\left(E_{\mathrm{u}} / \kappa T_{\mathrm{rot}}\right)}$

$N_{\mathrm{u}}=1.67 \times 10^{14} \frac{g_{\mathrm{u}}}{v \mu^{2} S} \int T_{\mathrm{A}}^{*} \mathrm{~d} v$

where $N_{\mathrm{u}}$ is the column density in the upper level of the observed transition in $\mathrm{cm}^{-2}, g_{\mathrm{u}}$ the upper level degeneracy $\left(2 J_{\mathrm{u}}+1\right), v$ the line frequency in $\mathrm{GHz}, \mu$ the dipole moment in Debye, $S$ the line strength, $\int T_{\mathrm{A}}^{*} \mathrm{~d} v$ the integrated intensity in $\mathrm{K} \mathrm{km} \mathrm{s}^{-1}$, $g_{i}$ the spin weight degeneracy, $Q$ the partition function, $E_{\mathrm{u}} / \kappa$ the upper level energy in $\mathrm{K}$, and $T_{\text {rot }}$ the rotational temperature also in $\mathrm{K}$. Table 3 summarizes the dipole moments, the rotational constants, the partition functions, and the statistical weights used to calculate the total column densities.

\subsubsection{Rotational temperatures}

To derive the total column densities one first needs to estimate $T_{\text {rot }}$. For molecules with more than one observed transition, we calculated $T_{\text {rot }}$ from population diagrams. Figure 4 
M. A. Requena-Torres et al.: Organic molecules in the GC
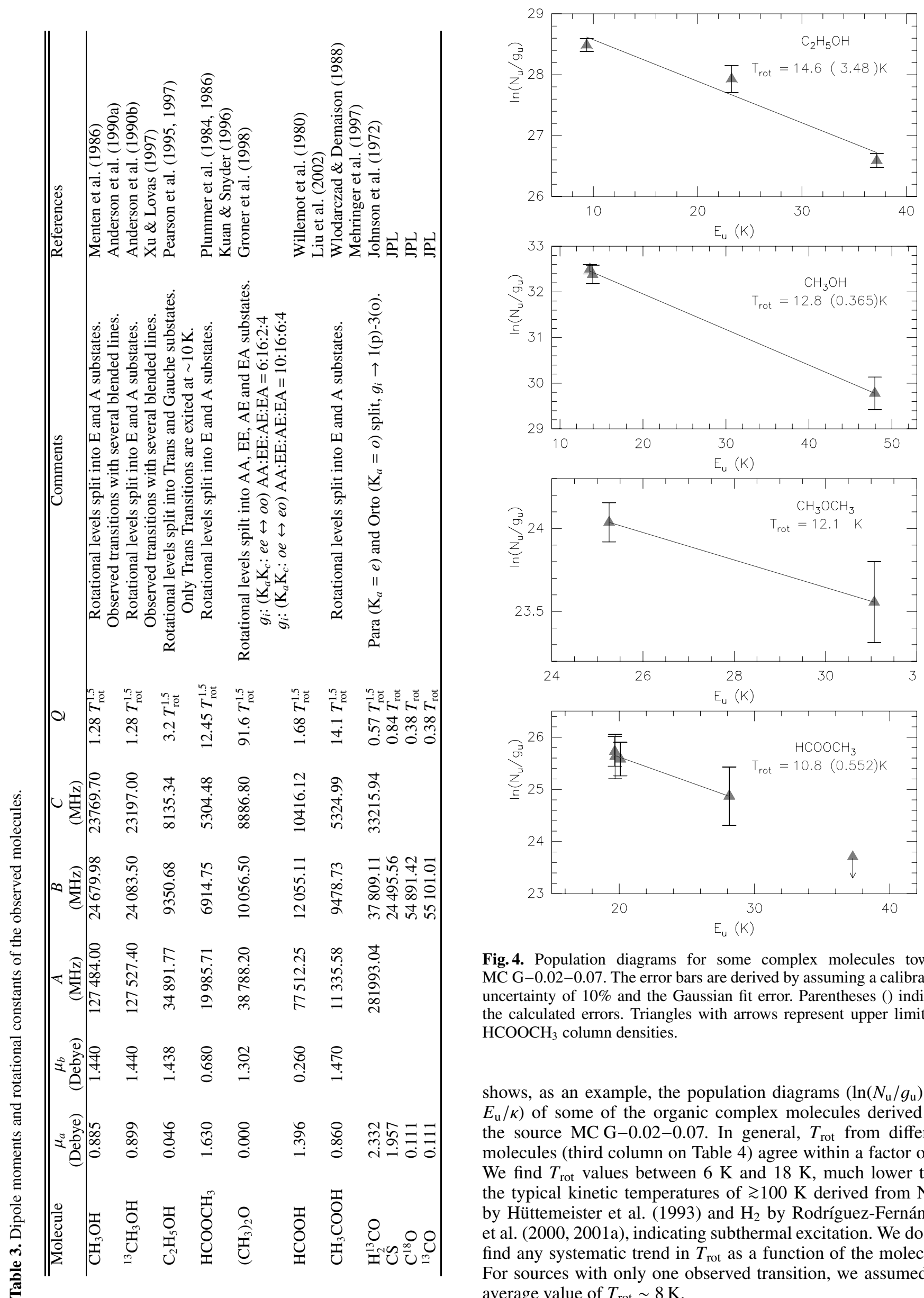

Fig. 4. Population diagrams for some complex molecules toward MC G-0.02-0.07. The error bars are derived by assuming a calibration uncertainty of $10 \%$ and the Gaussian fit error. Parentheses () indicate the calculated errors. Triangles with arrows represent upper limits to $\mathrm{HCOOCH}_{3}$ column densities.

shows, as an example, the population diagrams $\left(\ln \left(N_{\mathrm{u}} / g_{\mathrm{u}}\right)\right.$ vs. $\left.E_{\mathrm{u}} / \kappa\right)$ of some of the organic complex molecules derived for the source $\mathrm{MC} \mathrm{G}-0.02-0.07$. In general, $T_{\text {rot }}$ from different molecules (third column on Table 4) agree within a factor of 2. We find $T_{\text {rot }}$ values between $6 \mathrm{~K}$ and $18 \mathrm{~K}$, much lower than the typical kinetic temperatures of $\gtrsim 100 \mathrm{~K}$ derived from $\mathrm{NH}_{3}$ by Hüttemeister et al. (1993) and $\mathrm{H}_{2}$ by Rodríguez-Fernández et al. (2000, 2001a), indicating subthermal excitation. We do not find any systematic trend in $T_{\text {rot }}$ as a function of the molecule. For sources with only one observed transition, we assumed an average value of $T_{\text {rot }} \sim 8 \mathrm{~K}$. 


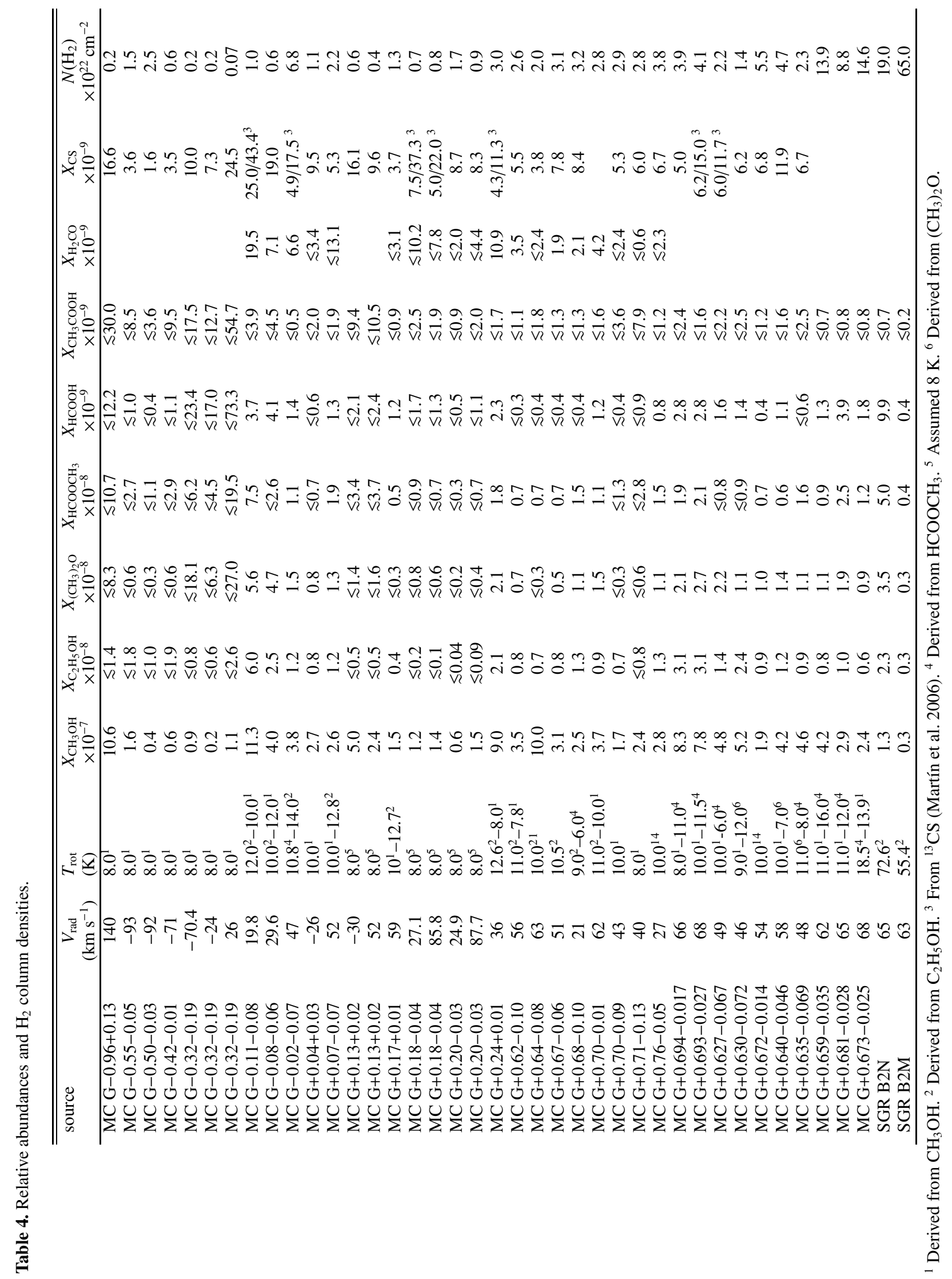




\subsubsection{Densities}

Once the $T_{\text {rot }}$ is derived, we can make a rough estimate of the $\mathrm{H}_{2}$ densities, providing that the kinetic temperatures and the collisional cross section are known. The $\mathrm{H}_{2}$ densities can be estimated from

$n=\frac{A_{\mathrm{ul}}}{\langle v \sigma\rangle_{\mathrm{ul}}} \frac{1+\left[1-\exp \left(\frac{h v}{k T_{\text {rot }}}\right)\right] \frac{1}{\exp \left(\frac{h v}{\kappa T_{\mathrm{bg}}}\right)-1}}{\exp \left(\frac{h v}{\kappa T_{\text {rot }}}\right) \exp \left(-\frac{h v}{\kappa T_{\mathrm{k}}}\right)-1}$

where $A_{\mathrm{ul}}$ is the Einstein coefficient between the upper and the lower levels, $\langle v \sigma\rangle_{\mathrm{ul}}$ the collisional rate coefficient between the same levels, $v$ the transition frequency, $h$ the Plank constant, $\kappa$ the Boltzmann constant, $T_{\text {rot }}$ the rotational temperature, $T_{\mathrm{bg}}$ the background temperature, and $T_{\mathrm{k}}$ the kinetic temperature. Pottage et al. (2004) have calculated the collision rate coefficients $(\langle v \sigma\rangle)$ between $\mathrm{E}-\mathrm{CH}_{3} \mathrm{OH}$ and para- $\mathrm{H}_{2}$ for kinetic temperatures between $5 \mathrm{~K}$ and $200 \mathrm{~K}$. Assuming a kinetic temperature of $100 \mathrm{~K}$ (Hüttemeister et al. 1993; Rodríguez-Fernández et al. 2001a), we obtain $\mathrm{H}_{2}$ densities of $\sim 10^{5} \mathrm{~cm}^{-3}$ for the rotational temperature derived from $\mathrm{CH}_{3} \mathrm{OH}$ of 6-18 K. Similar $\mathrm{H}_{2}$ densities are also derived when the measured line intensities of $\mathrm{E}-\mathrm{CH}_{3} \mathrm{OH}$ are fitted using the large velocity gradient (LVG) approximation model, provided by J. Cernicharo, for the excitation of $\mathrm{E}-\mathrm{CH}_{3} \mathrm{OH}$. We also estimated the $\mathrm{H}_{2}$ densities from the excitation temperatures derived from $\mathrm{C}_{2} \mathrm{H}_{5} \mathrm{OH}$. The collisional cross section in this case was estimated from those of $\mathrm{CH}_{3} \mathrm{OH}$ but corrected for the difference in mass and size. These roughly estimated $\mathrm{H}_{2}$ densities are also $\sim 10^{5} \mathrm{~cm}^{-3}$.

The derived $\mathrm{H}_{2}$ densities are based on the collisional rates for a kinetic temperature of $100 \mathrm{~K}$. However, the linewidths in the GC molecular clouds indicate the presence of supersonic turbulence and thus of non-equilibrium processes. In this case the collisional rates will not be described by the kinetic temperatures. However, for the observed transitions the rate coefficients do depend weakly on the increasing collisional velocities (Pottage et al. 2004), therefore our estimated densities will only be marginally affected by the effect of a larger velocity difference between the collisional partners than those represented by the kinetic temperature.

\subsubsection{The $\mathrm{H}_{2}$ column densities}

To estimate the $\mathrm{H}_{2}$ column density, we used the $J=1 \rightarrow 0$ and $J=2 \rightarrow 1 \mathrm{C}^{18} \mathrm{O}$ and the $J=1 \rightarrow 0{ }^{13} \mathrm{CO}$ transitions using the LTE approximation. We used the isotopic ratios of ${ }^{12} \mathrm{C} /{ }^{13} \mathrm{C}=$ $20,{ }^{16} \mathrm{O} /{ }^{18} \mathrm{O}=250$ (Wilson \& Rood 1994), and a CO relative abundance of $\mathrm{CO} / \mathrm{H}_{2}=10^{-4}$ (Frerking et al. 1982). The last column in Table 4 shows the derived $\mathrm{H}_{2}$ column densities. Our $\mathrm{H}_{2}$ column densities, derived from the LTE approximation, are within a factor of $\leq 2$ of those derived by Rodríguez-Fernández et al. (2001a) using the LVG approximation.

Table 4 also shows the relative CS abundance estimated from the CS column densities derived using the $T_{\text {rot }}$ obtained from $\mathrm{CH}_{3} \mathrm{OH}$. Since our data refer to the line emission of the main CS isotopomer, optical depth effects might affect the derived CS column densities (Hüttemeister 1993). We compared our results with those derived from ${ }^{13} \mathrm{CS}$ by Martín et al. (2006) in several common sources. The CS column densities derived from ${ }^{13} \mathrm{CS}$ are always higher than those of the CS by a factor of $1-5$. When the ${ }^{13} \mathrm{CS}$ determinations are available, Table 4 shows the two values estimated for the relative abundance of CS.

\subsubsection{Column densities of complex organic molecules}

To derive the column densities of the complex organic molecules we used the parameters in Table 3 and Eqs. (1) and (2). The relative abundance of complex molecules derived from their column densities and the $\mathrm{H}_{2}$ column densities are shown in Table 4.

\subsection{Abundances and abundance ratios}

Table 4 shows the derived rotation temperatures, fractional abundances, and the $\mathrm{H}_{2}$ column densities for the different molecular clouds. Different sources in the same line of sight are identified by their radial velocities. The fractional abundances of the complex organic molecules are very high, even higher than in the hot cores. The abundances we find reach values up to $1.1 \times 10^{-6}$ for $\mathrm{CH}_{3} \mathrm{OH}, 6 \times 10^{-8}$ for $\mathrm{C}_{2} \mathrm{H}_{5} \mathrm{OH}, 5.6 \times 10^{-8}$ for $\left(\mathrm{CH}_{3}\right)_{2} \mathrm{O}$, $7.5 \times 10^{-8}$ for $\mathrm{HCOOCH}_{3}, 4.1 \times 10^{-9}$ for $\mathrm{HCOOH}$, and $1.9 \times 10^{-8}$ for $\mathrm{H}_{2} \mathrm{CO}$. We have only obtained upper limits to the abundance of $\mathrm{CH}_{3} \mathrm{COOH}$ between $\leq 5 \times 10^{-10}$ and $\leq 5.5 \times 10^{-8}$.

There are some sources for which only upper limits to the abundances were measured for all the complex organic molecules except for $\mathrm{CH}_{3} \mathrm{OH}$. In some cases, like the sources with galactic longitude $\leq-0.30^{\circ}$, the upper limits to the abundances of all complex molecules are not relevant because of the lack of sensitivity of our observations. In this case the upper limits have not been included in the discussion. Other cases, like the $\mathrm{C}_{2} \mathrm{H}_{5} \mathrm{OH}$ upper limits toward MC G+0.18-0.04, MC G+0.20-0.03 (Sickle), and MC G+0.13+0.02 (TRA) are relevant and therefore included in our discussion. The molecular emission toward the Sickle shows two velocity components at $\sim 25 \mathrm{~km} \mathrm{~s}^{-1}$ and $\sim 80 \mathrm{~km} \mathrm{~s}^{-1}$, which are believed to be affected by the UV radiation produced by the Quintuplet cluster (Rodríguez-Fernández et al. 2001b). The molecular emission toward $\mathrm{MC} \mathrm{G}+0.13+0.02$, located in the TRA, also seems to be affected by the UV radiation from the Arches Cluster. In fact only the $-30 \mathrm{~km} \mathrm{~s}^{-1}$ velocity component, which is clearly associated with the ionized gas (Serabyn \& Güsten 1987), shows lower $\mathrm{C}_{2} \mathrm{H}_{5} \mathrm{OH}$ abundance than in other sources.

Because $\mathrm{CH}_{3} \mathrm{OH}$ is the only molecule that has been detected in all sources and it is believed to play a central role in the formation of some of the observed complex organic molecules, we compared the abundances of the rest of the complex molecules with that of $\mathrm{CH}_{3} \mathrm{OH}$. Figure 5 summarizes the results illustrating the abundance of all the observed molecules relative to that of $\mathrm{CH}_{3} \mathrm{OH}$ as a function of the $\mathrm{CH}_{3} \mathrm{OH}$ abundance. As already mentioned, we have only included the significant upper limits in this figure. The main results are:

- In spite of the $\mathrm{CH}_{3} \mathrm{OH}$ 's abundance changing by a factor of $\sim 50$, all the complex organic molecules, except that of the $\mathrm{CH}_{3} \mathrm{COOH}$ with only upper limits to its abundance, show a surprisingly constant relative abundance with respect to $\mathrm{CH}_{3} \mathrm{OH}$.

- The mean $\left[\mathrm{C}_{2} \mathrm{H}_{5} \mathrm{OH} / \mathrm{CH}_{3} \mathrm{OH}\right]$ abundance ratio of $\sim 3.6 \times 10^{-2}$ is constant within a factor 3.7. The Sickle and the TRA clouds show upper limits to the $\left[\mathrm{C}_{2} \mathrm{H}_{5} \mathrm{OH} / \mathrm{CH}_{3} \mathrm{OH}\right]$ ratios, which are a factor of $\gtrsim 6$ times lower than the mean ratio found in the typical GC clouds, a factor of $\gtrsim 1.6$ higher than the scattering of the data.

- The abundance ratios $\left[\left(\mathrm{CH}_{3}\right)_{2} \mathrm{O} / \mathrm{CH}_{3} \mathrm{OH}\right]$ and $\left[\mathrm{HCOOCH}_{3} / \mathrm{CH}_{3} \mathrm{OH}\right]$ present similar mean values of $\sim 3.9 \times 10^{-2}$. These ratios show a somewhat larger dispersion than that of $\mathrm{C}_{2} \mathrm{H}_{5} \mathrm{OH}$ but are constant within a factor of 7 .

- For the $\left[\mathrm{HCOOH} / \mathrm{CH}_{3} \mathrm{OH}\right]$ ratio, we obtained a mean value of $\sim 7.9 \times 10^{-3}$ and a dispersion of a factor of 5.3. 


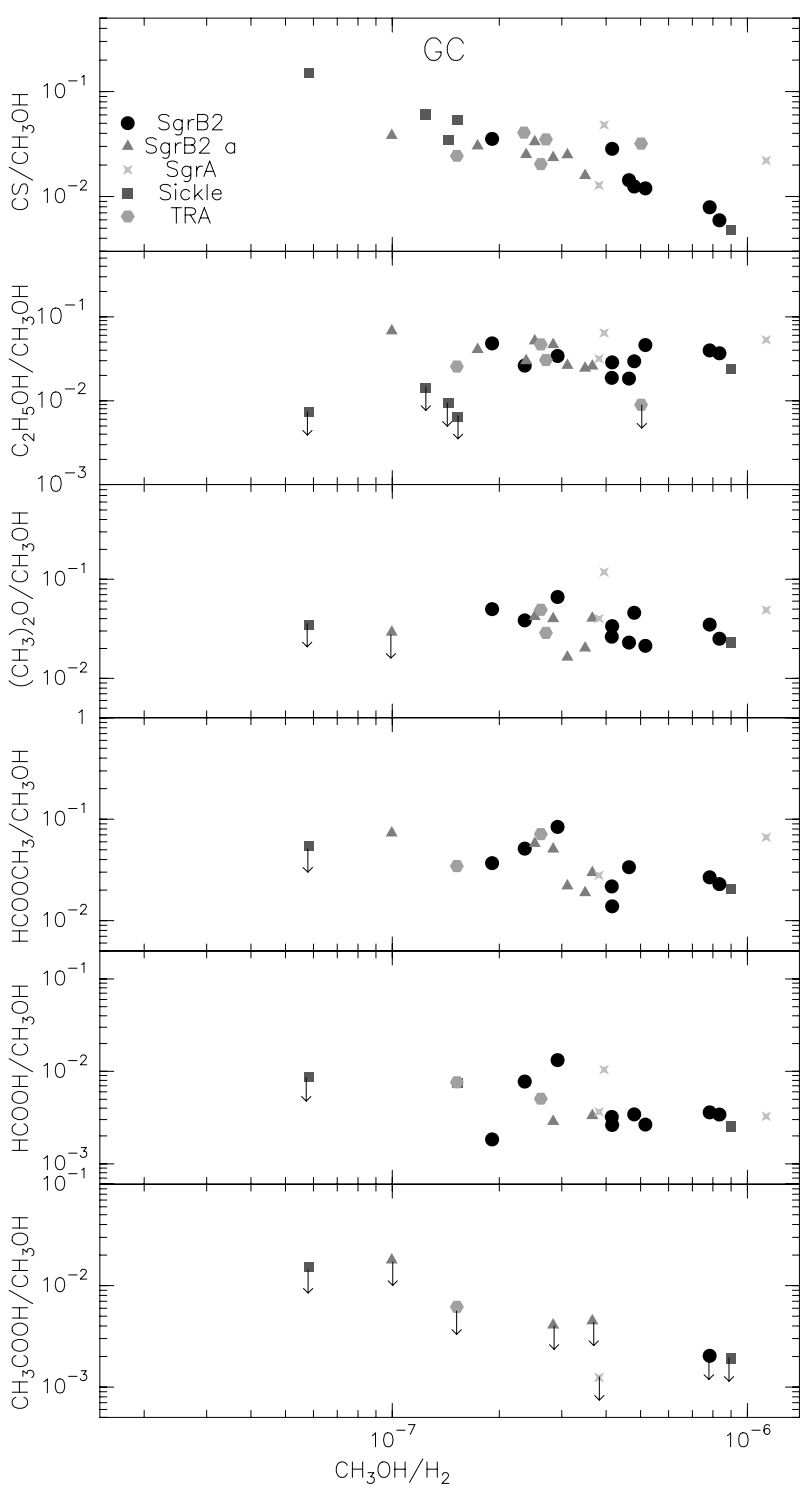

Fig. 5. Relative abundances of organic complex molecules with respect to $\mathrm{CH}_{3} \mathrm{OH}$ as a function of the $\mathrm{CH}_{3} \mathrm{OH}$ abundance for the selected $\mathrm{GC}$ clouds. Different regions are represented with different symbols (see Table 2). The arrows represent upper limits. Only the detections and significant upper limits are shown.

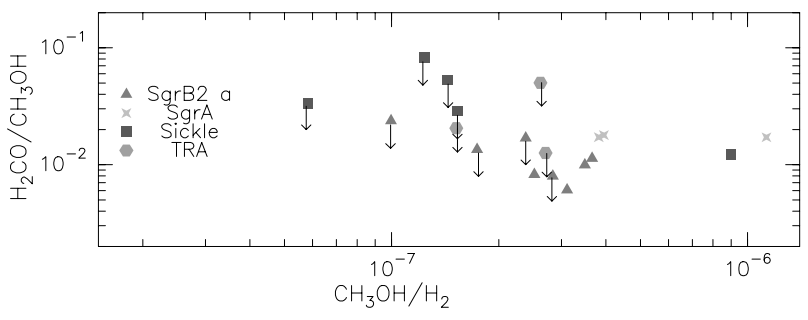

Fig. 6. Same as Fig. 5 but for $\mathrm{H}_{2} \mathrm{CO}$.

- $\mathrm{CH}_{3} \mathrm{COOH}$ was not been detected in the GC clouds but its $\left[\mathrm{CH}_{3} \mathrm{COOH} / \mathrm{CH}_{3} \mathrm{OH}\right]$ ratio must be lower than $10^{-3}$.

- We also show in Fig. 6 the $\left[\mathrm{H}_{2} \mathrm{CO} / \mathrm{CH}_{3} \mathrm{OH}\right]$ ratio as a function of the $\mathrm{CH}_{3} \mathrm{OH}$ abundance. As for the more complex organic molecules, we find a constant ratio of $\sim 1.1 \times 10^{-2}$, within a factor 3 .

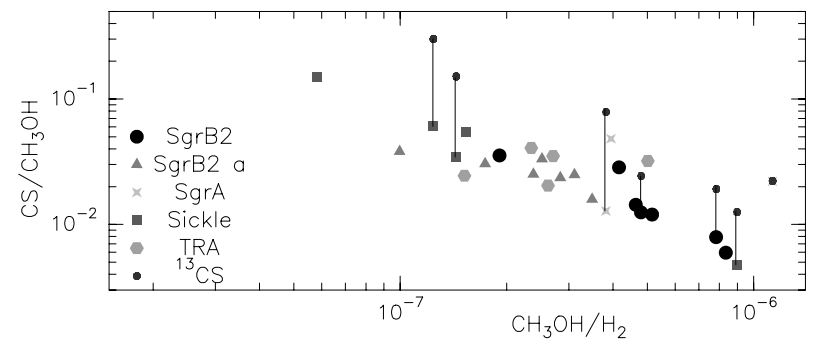

Fig. 7. Variation of $\left[\mathrm{CS} / \mathrm{CH}_{3} \mathrm{OH}\right]$ as a function of $\mathrm{CH}_{3} \mathrm{OH}$ abundances. The vertical bars show the changes due to the opacity.

The $\left[\mathrm{CS} / \mathrm{CH}_{3} \mathrm{OH}\right]$ abundance ratio is shown in Fig. 7. This abundance ratio decreases by a factor 60 as the $\mathrm{CH}_{3} \mathrm{OH}$ abundance increases. This is the only molecule for which we find a systematic trend, and the variation is clearly larger than those found for the complex organic molecules. As previously mentioned, our CS column densities could be affected by opacity effects. To show the effects of opacity, we have also included the abundance ratio obtained using the rarer $\mathrm{CS}$ isotopomer ${ }^{13} \mathrm{CS}$ in Fig. 7 as vertical bars. The $\left[\mathrm{CS} / \mathrm{CH}_{3} \mathrm{OH}\right]$ abundance ratio derived from the optically thin isotopomer increases by a relatively constant value for all clouds independently of the $\mathrm{CH}_{3} \mathrm{OH}$ abundance. The variation observed in the $\left[\mathrm{CS} / \mathrm{CH}_{3} \mathrm{OH}\right]$ ratio as a function of the $\mathrm{CH}_{3} \mathrm{OH}$ abundance, using the ${ }^{13} \mathrm{CS}$ data, is similar or even larger than that derived from the CS data. We therefore consider that the difference between the behavior of $\mathrm{CS}$ and the complex organic molecules is real and related to the different type of chemistry in the GC clouds.

\section{Comparison with Galactic disk objects}

In dark clouds, where the kinetic temperature is only $10 \mathrm{~K}$, the abundance of complex organic molecules is very low. In the dark cloud TMC-1, the $\mathrm{CH}_{3} \mathrm{OH}, \mathrm{H}_{2} \mathrm{CO}$, and $\mathrm{HCOOH}$ abundances are as low as $2 \times 10^{-9}, 2 \times 10^{-8}$, and $3 \times 10^{-10}$, respectively (see e.g. Turner 2000). For other dark clouds like L183, one finds similar abundances of $8 \times 10^{-9}$ for $\mathrm{CH}_{3} \mathrm{OH}$, of $2 \times 10^{-8}$ for $\mathrm{H}_{2} \mathrm{CO}$, and of $3 \times 10^{-10}$ for $\mathrm{HCOOH}$ (Turner et al. 1999; Dickens et al. 2000). Other complex molecules, like $\mathrm{C}_{2} \mathrm{H}_{5} \mathrm{OH}$, $\left(\mathrm{CH}_{3}\right)_{2} \mathrm{O}, \mathrm{CH}_{3} \mathrm{COOH}$, and $\mathrm{HCOOCH}_{3}$, have not been detected so far, but model predictions suggest $\mathrm{C}_{2} \mathrm{H}_{5} \mathrm{OH}$ abundances of $10^{-12}$ (Hasegawa \& Herbst 1993). High abundance of the complex organic molecules were first observed in the short-lived $\left(10^{5-6}\right.$ years) objects associated with massive star-forming regions known as hot cores. There, it is believed that grain mantle evaporation release complex molecules, like alcohols, into gas phase. Recently, Bottinelli et al. (2004a,b, 2006) and Kuan et al. (2004) detected relatively large abundances of complex organic molecules, like $\mathrm{HCOOCH}_{3}$ and $\left(\mathrm{CH}_{3}\right)_{2} \mathrm{O}$, toward the so-called "hot corinos" associated with warm condensation surrounding low mass proto-stars.

In the following sections, we compare the abundances of complex organic molecules in the GC with those found in the hot cores and hot corinos associated with star formation.

\subsection{Hot cores}

For the comparison between the GC and hot cores associated to massive star formation, we selected the homogeneous data set by Ikeda et al. (2001) for several hot cores (W51, NGC6334f, G327.3-0.6, G31.41+0.31, G34.3+0.2, G10.47+0.03, and the Orion Hot Core). We also used data from 
Table 5. Hot core abundances.

\begin{tabular}{|c|c|c|c|c|c|c|c|c|}
\hline Source & $\begin{array}{l}X_{\mathrm{CH}_{3} \mathrm{OH}} \\
\times 10^{-7}\end{array}$ & $\begin{array}{c}X_{\mathrm{C}_{2} \mathrm{H}_{5} \mathrm{OH}} \\
\times 10^{-8}\end{array}$ & $\begin{array}{c}X_{\left(\mathrm{CH}_{3}\right)_{2} \mathrm{O}} \\
\times 10^{-8}\end{array}$ & $\begin{array}{c}X_{\mathrm{HCOOCH}_{3}} \\
\times 10^{-8}\end{array}$ & $\begin{array}{l}X_{\mathrm{HCOOH}} \\
\times 10^{-9}\end{array}$ & $\begin{array}{c}X_{\mathrm{CH}_{3} \mathrm{COOH}} \\
\times 10^{-9}\end{array}$ & $\begin{array}{l}X_{\mathrm{H}_{2} \mathrm{CO}} \\
\times 10^{-8}\end{array}$ & $\begin{array}{c}N\left(\mathrm{H}_{2}\right) \\
\times 10^{22} \mathrm{~cm}^{-2}\end{array}$ \\
\hline \multicolumn{9}{|l|}{ High mass $^{a}$} \\
\hline W51 e1/e2 & 3.0 & 0.9 & & 3.0 & & $0.3-1.8$ & & 36 \\
\hline NGC6334f & 2.0 & 0.9 & 4.0 & & 1.0 & & & 20 \\
\hline G327.3-0.6 & 1.0 & 1.0 & 3.0 & & 0.9 & & & 20 \\
\hline G31.41+0.31 & 0.9 & 2.0 & 2.0 & & 1.0 & & & 16 \\
\hline G34.3+0.2 & 0.9 & 0.6 & 1.0 & 0.5 & & 0.2 & & 30 \\
\hline $\mathrm{G} 10.47+0.03$ & 2.0 & 1.0 & 3.0 & & 1.0 & & & 13 \\
\hline Omc HC & 10.0 & 2.0 & & 9.0 & & & & 10 \\
\hline \multicolumn{9}{|l|}{ Low mass ${ }^{b}$} \\
\hline IRAS 4A & $\lesssim 0.1$ & & $\lesssim 2.8$ & 6.8 & 4.6 & & 2.0 & 160 \\
\hline IRAS 4B & 7.0 & & $\lesssim 120.0$ & 220.0 & $\lessgtr 1000$ & & 300.0 & 8.1 \\
\hline IRAS 2A & 3.0 & & 3.0 & $\lessgtr 134.0$ & $\lessgtr 120$ & & 20.0 & 21 \\
\hline IRAS 16293 & 1.0 & & 24.0 & 34.0 & $\sim 62$ & & 10.0 & 7.5 \\
\hline
\end{tabular}

${ }^{a}$ Ikeda et al. (2001) and Remijan et al. (2002, 2003); ${ }^{b}$ Bottinelli et al. (2006).

Table 6. Summary of chemical models and observations of complex organic molecules.

\begin{tabular}{|c|c|c|c|c|c|c|c|}
\hline Source & $\begin{array}{c}T \\
(\mathrm{~K})\end{array}$ & $\begin{array}{l}n\left(\mathrm{H}_{2}\right) \\
\left(\mathrm{cm}^{-3}\right)\end{array}$ & $\begin{array}{l}\frac{\mathrm{C}_{2} \mathrm{H}_{5} \mathrm{OH}}{\mathrm{CH}_{3} \mathrm{OH}} \\
\times 10^{-2} \\
\end{array}$ & $\begin{array}{l}\frac{\left(\mathrm{CH}_{3}\right)_{2} \mathrm{O}}{\mathrm{CH}_{3} \mathrm{OH}} \\
\times 10^{-2}\end{array}$ & $\begin{array}{l}\frac{\mathrm{HCOOCH}_{3}}{\mathrm{CH}_{3} \mathrm{OH}} \\
\times 10^{-2}\end{array}$ & $\frac{\mathrm{H}_{2} \mathrm{CO}}{\mathrm{CH}_{3} \mathrm{OH}}{ }^{a}$ & $\begin{array}{c}\text { age } \\
\times 10^{5} \mathrm{y}\end{array}$ \\
\hline Galactic center clouds & $\sim 100^{b}$ & $\sim 10^{4}-10^{5}$ & $\sim 3.66$ & $\sim 3.87$ & $\sim 3.96$ & $\sim 1.10 \times 10^{-2}$ & \\
\hline hot $\operatorname{cores}^{c}$ & $\sim 100$ & $\sim 10^{6}$ & $\sim 6.90$ & $\sim 21.80$ & $\sim 8.03$ & & \\
\hline Leung et al. (1984) ${ }^{d}$ & 10 & $10^{4}$ & 0.14 & 6.00 & & 43.6 & 3.16 \\
\hline Herbst \& Leung $(1986)^{e}$ & 10 & $10^{4}$ & 2.18 & 5.25 & & 9.75 & 3.20 \\
\hline Herbst \& Leung $(1989)^{e}$ & 10 & $10^{4}$ & 0.99 & 0.12 & & 65.5 & 1.00 \\
\hline Millar et al. $(1991)^{d}$ & 70 & $2 \times 10^{5}$ & 0.19 & $6.32 \times 10^{-2}$ & 1.26 & $1.18 \times 10^{3}$ & 1.60 \\
\hline Hasegawa \& Herbst $(1993)^{f}$ & 10 & $10^{4}$ & 0.77 & $1.56 \times 10^{-2}$ & & $4.06 \times 10^{2}$ & 3.20 \\
\hline Caselli et al. (1993)-CR ${ }^{g}$ & 100 & $10^{6}$ & $1.5 \times 10^{-4}$ & 0.21 & $4.67 \times 10^{-3}$ & 1.05 & 1.00 \\
\hline Charnley et al. (1995) & 100 & $2 \times 10^{6}$ & & $\sim 2$ & $\sim 1.5$ & $4 \times 10^{-2}$ & $\sim 0.30$ \\
\hline Rodgers \& Charnley $(2001)^{h}$ & 100 & $10^{7}$ & 3.75 & 30.00 & 10.00 & & 0.12 \\
\hline Rodgers \& Charnley $(2001)^{i}$ & 100 & $10^{7}$ & 20.00 & 12.50 & 0.50 & & 0.60 \\
\hline Horn et al. $(2004)^{j}$ & 100 & $10^{6}$ & & 0.75 & $3.33 \times 10^{-2}$ & 1.56 & 0.80 \\
\hline Peeters et al. $(2006)^{k}$ & 100 & $10^{7}$ & & 50.00 & & & 0.20 \\
\hline
\end{tabular}

${ }^{a}$ The relative abundances of $\mathrm{C}_{2} \mathrm{H}_{5} \mathrm{OH},\left(\mathrm{CH}_{3}\right)_{2} \mathrm{O}, \mathrm{HCOOCH}_{3}$, and $\mathrm{H}_{2} \mathrm{CO}$ with respect to $\mathrm{CH}_{3} \mathrm{OH}$ predicted by time-dependent chemical models, refer to the age of maximum abundance of the $\mathrm{CH}_{3} \mathrm{OH}$ 's daughters; ${ }^{b}$ from Hüttemeister et al. (1993) and Rodríguez-Fernández et al. (2001a); ${ }^{c}$ mean abundance ratios for the hot core sources used in this work; ${ }^{d}$ model 1 of the referred paper; ${ }^{e}$ low-metal model in the referred paper; ${ }^{f}$ model starting with all the $\mathrm{H}$ in $\mathrm{H}_{2} ;{ }^{g}$ model fixed with the Orion Compact ridge observations; ${ }^{h}$ model without $\mathrm{NH}_{3} ;{ }^{i}$ model with $\mathrm{NH}_{3} ;{ }^{j}$ model 3 of the referred paper; ${ }^{k}$ model with $\left(\mathrm{CH}_{3}\right)_{2} \mathrm{O}$ created only in gas phase.

Remijan et al. $(2002,2003)$ to obtain the $\mathrm{CH}_{3} \mathrm{COOH}$ abundances derived from their $\left[\mathrm{HCOOCH} 3 / \mathrm{CH}_{3} \mathrm{COOH}\right]$ ratio. The hot cores abundances of complex molecules and the $\mathrm{H}_{2}$ column densities are given in Table 5. Both the $\mathrm{H}_{2}$ and molecular column densities were derived from observations with similar beam sizes. Then the derived fractional abundances are independent of beam dilution. Since our comparation is based on the relative abundance between complex molecules, our results are not affected by the size of the hot cores.

We also used our data for the Sgr B2N and Sgr B2M hot cores in Table 4. Figure 8 illustrates the comparison between the abundance ratios observed for the $\mathrm{GC}$ and those measured in hot cores. As for the $\mathrm{GC}$ clouds, the abundance of $\mathrm{CH}_{3} \mathrm{OH}$ in hot cores shows variations of more than one order of magnitude between different objects. Surprisingly, the abundance ratios relative to $\mathrm{CH}_{3} \mathrm{OH}$ are also independent of the $\mathrm{CH}_{3} \mathrm{OH}$ abundance and similar to those measured for the GC clouds. The $\mathrm{C}_{2} \mathrm{H}_{5} \mathrm{OH}$ and $\mathrm{HCOOH}$ mean abundance ratios with respect to $\mathrm{CH}_{3} \mathrm{OH}$ between hot cores and GC clouds are different by less than a factor of 2. The molecule that presents the largest difference in its abundance ratio with respect to that in the $\mathrm{GC}$ clouds is $\left(\mathrm{CH}_{3}\right)_{2} \mathrm{O}$ with a mean ratio of $2 \times 10^{-1}$, which is $\sim 6$ times higher than those of the $\mathrm{GC}$ clouds. The $\left[\mathrm{CH}_{3} \mathrm{COOH} / \mathrm{CH}_{3} \mathrm{OH}\right]$ ratios in hot cores agree with the upper-limit ratios found in GC clouds. Our data for the Sgr B2N Hot Core shows slightly higher abundances of $\mathrm{HCOOCH}_{3}$ and $\mathrm{HCOOH}$ than the rest of the hot cores. The Sgr B2M Hot Core, with the lowest $\mathrm{CH}_{3} \mathrm{OH}$ abundance, shows similar ratios to those in the GC sources.

It is remarkable that different objects like the hot cores and the GC clouds, with different properties in terms of densities, $\mathrm{H}_{2}$ column densities, and spatial extension, show such uniform abundance ratios of very complex molecules. Hot cores are denser than the GC clouds by more than 2 orders of magnitude, and they typically have larger column densities than the GC clouds.

\subsection{Hot corinos}

Bottinelli et al. (2004a,b, 2006), Jørgensen et al. (2005) and Kuan et al. (2004) observed the hot corinos associated with the 


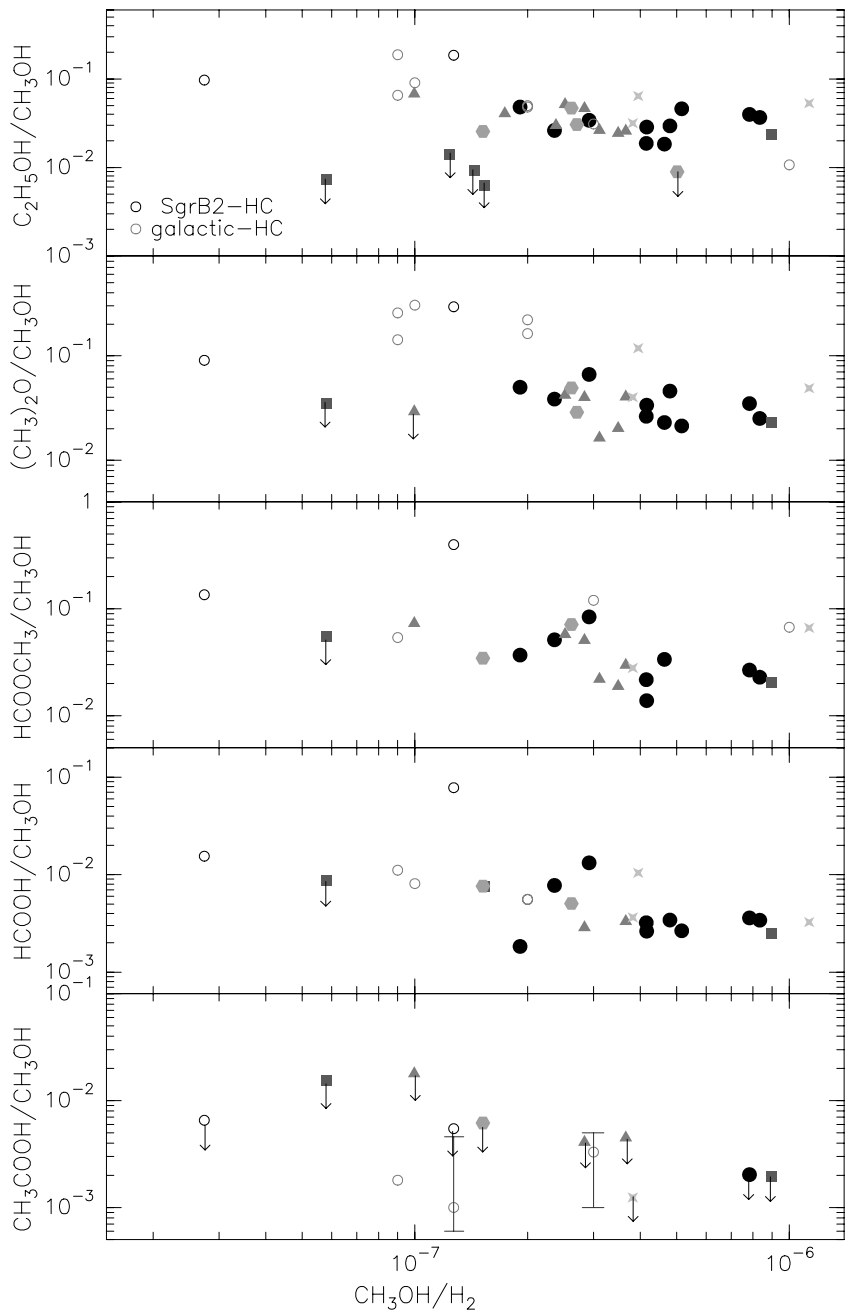

Fig. 8. Same as Fig. 5 but including the hot core abundances obtained from Ikeda et al. (2001), Remijan et al. (2002, 2003), and from our SGR B2 data as open symbols.

low mass proto-stars, NGC1333 IRAS 4A, NGC1333 IRAS 4B, NGC1333 IRAS 2A and IRAS 16293-2422 (A and B), which also show large abundances of $\mathrm{HCOOCH}_{3}, \mathrm{H}_{2} \mathrm{CO},\left(\mathrm{CH}_{3}\right)_{2} \mathrm{O}$ and $\mathrm{HCOOH}$. Table 5 summarizes the recent compilation of the hot corino abundances of complex organic molecules by Bottinelli et al. (2006). In this case the molecular abundances were derived by assuming a source size of $0.5^{\prime \prime}$ for IRAS 4 A (Bottinelli et al. 2004a), $0.25^{\prime \prime}$ for IRAS 4B, $0.43^{\prime \prime}$ for IRAS 2A (Maret et al. 2004), and $2^{\prime \prime}$ for IRAS 16293-2422 (Cazaux et al. 2003).

Except for IRAS 4A, which shows lower abundances, $\mathrm{HCOOCH}_{3},\left(\mathrm{CH}_{3}\right)_{2} \mathrm{O}, \mathrm{HCOOH}$, and $\mathrm{H}_{2} \mathrm{CO}$ show higher abundances in hot corinos than in the GC molecular clouds and hot cores. The data show that the abundance of $\mathrm{CH}_{3} \mathrm{OH}$ varies between sources by nearly two orders of magnitude, similar to the variation observed in the GC clouds. As in the GC molecular clouds and in the hot cores, the abundance of the complex organic molecules relative to that of $\mathrm{CH}_{3} \mathrm{OH}$ is independent of the $\mathrm{CH}_{3} \mathrm{OH}$ abundance for different hot corinos (Bottinelli et al. 2006).

Although the number of observations of hot corinos is still limited, it seems that the abundance ratios, including species believed to be formed by different chemistries, show a similar behavior to the GC sources. However, the abundance of the molecules is very different, as expected if the grain mantle composition in dark clouds were different than in the GC clouds and hot cores.

\section{Discussion}

With the exception of the clouds associated with the Sickle and the TRA, large abundances of organic complex molecules like $\mathrm{CH}_{3} \mathrm{OH}, \mathrm{C}_{2} \mathrm{H}_{5} \mathrm{OH},\left(\mathrm{CH}_{3}\right)_{2} \mathrm{O}, \mathrm{HCOOCH}_{3}, \mathrm{HCOOH}$, and $\mathrm{H}_{2} \mathrm{CO}$ seems to be a general characteristic of molecular clouds in the GC at scales of a few hundred parsecs. The main characteristic of the GC molecular gas is that the complex organic molecules show a constant relative abundance with respect to $\mathrm{CH}_{3} \mathrm{OH}$, within a factor 4-8 over the whole range of the $\mathrm{CH}_{3} \mathrm{OH}$ abundances in the observed $\mathrm{GC}$ clouds. This contrasts with the $\left[\mathrm{CS} / \mathrm{CH}_{3} \mathrm{OH}\right]$ abundance ratio that increases by a factor of 60 when the $\mathrm{CH}_{3} \mathrm{OH}$ abundance decreases.

We now discuss the origin of the chemistry of the complex molecules found in the GC sources, including the low $\left[\mathrm{C}_{2} \mathrm{H}_{5} \mathrm{OH} / \mathrm{CH}_{3} \mathrm{OH}\right]$ abundance ratio measured in the Sickle and the TRA clouds.

\subsection{Models for gas-phase formations of organic molecules}

Table 6 shows a compilation of the models proposed to explain the formation of complex organic molecules. Since gas-phase chemistry cannot account for the large abundance of alcohols, such as $\mathrm{CH}_{3} \mathrm{OH}$ and $\mathrm{C}_{2} \mathrm{H}_{5} \mathrm{OH}$, or for other organic molecules like the $\mathrm{H}_{2} \mathrm{CO}$ measured in hot cores, evaporation from grain mantles has been proposed as the main formation mechanism. Most of these models assume that $\left(\mathrm{CH}_{3}\right)_{2} \mathrm{O}$ and $\mathrm{HCOOCH}_{3}$ were produced in gas phase after the ejection of $\mathrm{CH}_{3} \mathrm{OH}$. However, it has been recently claimed that $\mathrm{HCOOCH}_{3}$ cannot be produced efficiently in gas phase from $\mathrm{CH}_{3} \mathrm{OH}$ (Horn et al. 2004). The large abundances of this molecule found in the GC clouds clearly indicate that $\mathrm{HCOOCH}_{3}$ is hardly likely to be produced in gas phase. However, the most recent model from Peeters et al. (2006) studied the possibilities for the formation of $\left(\mathrm{CH}_{3}\right)_{2} \mathrm{O}$ on grain mantles and concluded that the gas-phase reactions are the dominant way to form $\left(\mathrm{CH}_{3}\right)_{2} \mathrm{O}$, while grain mantle reactions are the minor source.

From the theoretical point of view, so far, only $\left(\mathrm{CH}_{3}\right)_{2} \mathrm{O}$ seems to be produced in gas phase from reactions involving $\mathrm{CH}_{3} \mathrm{OH}$ on relatively short time scales. Assuming that the gas phase models for the $\left(\mathrm{CH}_{3}\right)_{2} \mathrm{O}$ formation are correct (see references in Table 6), one would expect large changes in the relative abundances between the daughter $\left(\left(\mathrm{CH}_{3}\right)_{2} \mathrm{O}\right)$ and parent $\left(\mathrm{CH}_{3} \mathrm{OH}\right)$ molecules as a function of time after ejection/evaporation. One expects low $\left[\left(\mathrm{CH}_{3}\right)_{2} \mathrm{O} / \mathrm{CH}_{3} \mathrm{OH}\right]$ abundance ratio in early times just when large abundances of $\mathrm{CH}_{3} \mathrm{OH}$ are ejected into the gas phase and the gas phase processing starts. Low $\left[\left(\mathrm{CH}_{3}\right)_{2} \mathrm{O} / \mathrm{CH}_{3} \mathrm{OH}\right]$ ratios are also expected in late times in the low $\mathrm{CH}_{3} \mathrm{OH}$ abundance regime when an important fraction of $\mathrm{CH}_{3} \mathrm{OH}$ has been converted into daughter molecules and both molecules have been destroyed by gas-phase reactions. Between these two regimes, one would expect the $\left[\left(\mathrm{CH}_{3}\right)_{2} \mathrm{O} / \mathrm{CH}_{3} \mathrm{OH}\right]$ ratio to reach its maximum values, because the daughter molecules reach their maximum abundance.

From the hot core models, one expects variations in $\left[\left(\mathrm{CH}_{3}\right)_{2} \mathrm{O} / \mathrm{CH}_{3} \mathrm{OH}\right]$ abundance ratio up to three orders of magnitude as a function of time. This contrasts with our data for the GC clouds and the hot cores, which show variations of less than one order of magnitude. Assuming that the chemical models for hot 
cores are applicable in the GC, the only possibility of explaining the high abundances of complex molecules and the rather constant $\left[\left(\mathrm{CH}_{3}\right)_{2} \mathrm{O} / \mathrm{CH}_{3} \mathrm{OH}\right]$ abundance ratios is to consider that all GC clouds in our study, distributed over $200 \mathrm{pc}$, have undergone the ejection of $\mathrm{CH}_{3} \mathrm{OH}$ from grain mantles nearly simultaneously, $\sim 10^{5}$ years ago. This possibility seems very unlikely, suggesting that $\left(\mathrm{CH}_{3}\right)_{2} \mathrm{O}$ is also ejected from grain mantels. Since $\left(\mathrm{CH}_{3}\right)_{2} \mathrm{O}$ shows similar abundances with respect to $\mathrm{CH}_{3} \mathrm{OH}$ than the other molecules that can only be formed on grain mantles like $\mathrm{C}_{2} \mathrm{H}_{5} \mathrm{OH}$ and $\mathrm{HCOOCH}_{3}$, our data support the scenario in which all complex organic molecules in the GC clouds, the hot cores, and also in hot corinos have been ejected/evaporated from grains.

Previously we also found differences in the behavior of the relative abundances of CS and the complex organic molecules. This behavior is supported by the data in shock regions associated with outflows, as in L1448 (Jiménez-Serra et al. 2005) and L1157 (Bachiller \& Pérez Gutiérrez 1997). The CS abundance is enhanced by the shock, but the enhancement of $\mathrm{CH}_{3} \mathrm{OH}$ is $\sim 1$ order of magnitude larger than that of CS. This effect of differential ejection of the molecules can explain the variation in the complex organic molecules abundances in gas phase, while the CS abundance remains marginally affected.

\subsection{Grain mantle erosion by shocks and time scales for depletion}

In the GC clouds, the typical dust-grain temperatures are low ( $T \sim 10-30 \mathrm{~K}$, Rodríguez-Fernández et al. 2004) and the ejection of molecules to gas phase cannot be produced by evaporation like in hot cores, but by shocks with moderate velocities. The shock heats the gas and produces the sputtering of molecules on the grain mantles. For shock velocities of $\sim 20 \mathrm{~km} \mathrm{~s}^{-1}$, the gas temperature can reach $\sim 1000 \mathrm{~K}$ (Kaufman \& Neufeld 1996). After the shock passage, the gas rapidly cools on time scales of $\sim 10^{4}$ years for densities of $10^{5} \mathrm{~cm}^{-3}$. The complex molecules ejected from the grains will again stick to the grains or grain mantles. The time scales will depend on the sticking coefficient. A sticking coefficient of $\sim 1$ is expected for mean velocities corresponding to the thermal velocity at temperatures of $\lesssim 200 \mathrm{~K}$ because the complex molecules will be absorbed after every collision with a grain (Tielens \& Hagen 1982). However, the sticking coefficient decreases when increasing the relative velocity between the grains and the molecules (Leitch-Devlin \& Williams 1985). Buch \& Zhang (1991) and Masuda et al. (1998) estimated that the sticking coefficient of $\mathrm{H}$ is a function of the mean velocity.

The key parameter is the adsorption energy of the complex molecules, which will depend on the surface of the dust grains. Since the $\mathrm{CH}_{3} \mathrm{OH}$ abundance in gas phase is relatively large, grain mantles are completely eroded and the most likely grain surfaces in the GC clouds would be graphite and silicates. The absorption energy of $\mathrm{CH}_{3} \mathrm{OH}$ on carbon basal planes is $1600 \mathrm{~K}$ (Aikawa et al. 1996) and on silicates is $2065 \mathrm{~K}$ (Allen \& Robinson 1977). For the typical mean velocities in the GC of $2-$ $4 \mathrm{~km} \mathrm{~s}^{-1}$ (see next section) the sticking coefficient will decrease and the time scale for sticking would be $\sim 10^{5}$ years on silicates and graphites. Similar time scales are found for the depletion of $\mathrm{C}_{2} \mathrm{H}_{5} \mathrm{OH}, \mathrm{HCOOCH}_{3}$, and $\left(\mathrm{CH}_{3}\right)_{2} \mathrm{O}$ molecules with absorption energies $23000 \mathrm{~K}$ on silicates (Allen \& Robinson 1977). Short time scales for depletion, like those expected in the GC, would require a mechanism that continuously ejects molecules from the grain mantles.

\subsection{Origin of the shocks in the GC}

Rodríguez-Fernández et al. (2001a, 2004) have summarized the possible mechanisms for the heating and the chemistry of the molecular gas in the GC. Turbulence and low-velocity shocks are proposed as the most likely mechanism for driving the chemistry. One of the key parameters for constraining the origin of the shocks is the velocity dispersion in the GC molecular clouds. High angular-resolution observation of the envelope of Sgr B2 indicates that the warm molecular gas is highly turbulent with linewidths of $\sim 4 \mathrm{~km} \mathrm{~s}^{-1}$ (Martín-Pintado et al. 1999). Smith et al. (2000) show that MHD turbulence creates a wide range of shock velocities, but the larger amount of them should be produced with Mach numbers between 2-4. In the GC regions the sound speed is $\sim 1 \mathrm{~km} \mathrm{~s}^{-1}$ (at $100 \mathrm{~K}$ ), and then the more abundant shocks associated with turbulence should have velocities between 2 and $4 \mathrm{~km} \mathrm{~s}^{-1}$, in agreement with the linewidth measured from high angular-resolution observations. As discussed in the previous section, for a mean velocity of $\sim 3 \mathrm{~km} \mathrm{~s}^{-1}$, the depletion will be $\sim 10^{5}$ years.

The energy of any kind of turbulence will decay if there is not any source injecting new energy. It is interesting to compare the depletion time scales with the turbulence decay time scales to establish if the turbulence can maintain mean velocities that are high enough to match the depletion time scales. The turbulence decays as $t^{-\alpha}$, where $\alpha \sim 0.8-1.0$ (Mac Low et al. 1998; Stone et al. 1998). The decay time scale of these turbulences is similar to one dynamical time $\left(t_{\text {dyn }}=L / \sigma_{v}\right.$, where $L$ is the turbulent length and $\sigma_{v}$ the turbulent velocity, Avila-Reese \& Vázquez-Semadeni 2001; Elmegreen \& Scalo 2004), for both HD and MHD turbulence. The dynamical time for turbulence in the GC, assuming a turbulent length of $5 \mathrm{pc}$ and a turbulent velocity dispersion of $15 \mathrm{~km} \mathrm{~s}^{-1}$ (observed GC linewidths), is $\sim 3 \times 10^{5}$ years, close to the depletion time scale. Since we do not observe large depletions in our data, the existence of faster shocks with velocities high enough to produce the sputtering of the grain mantles and with the time scales between shocks similar to the time scales for depletion, $\sim 10^{5}$ years is required. Shocks with velocities of $\gtrsim 6 \mathrm{~km} \mathrm{~s}^{-1}$ are required in order to sputter molecules from the icy mantles on graphite and silicate grains by heavy atoms (Draine \& Salpeter 1979). Then, if due to a sudden event, the turbulence generated by this event could explain the presence of complex organic molecules in the GC clouds for $\sim 10^{5}$ years.

It is so far unclear what produces the supersonic turbulence and/or frequent shocks in the GC. The high-velocity shocks and the presence of a highly turbulent medium in the GC could be due to: a) the kinematics of the gas subjected to the barred potential of our Galaxy, b) the wind-blown bubbles produced in evolved massive stars like supernovas, or c) cloud-cloud collisions. The time scales needed in the GC to maintain the large abundances are much smaller than those associated to the quasicircular orbits $\left(\sim 1 \times 10^{7}\right.$ years $)$, and a large number of large scale shocks would be required to explain the observed properties of the complex molecules. The other possible mechanisms could explain the observations if cloud-cloud collision and energetic events driven by massive stars occur on time scales of $10^{5}$ years. In the scenario of a recent star burst in the GC as proposed to explain the fine structure lines of ionized gas (Rodríguez-Fernández \& Martín-Pintado 2005), frequent energetic events associated to massive stars are expected to produce shocks with moderate velocities of $\sim 10 \mathrm{~km} \mathrm{~s}^{-1}$ (Martín-Pintado et al. 1999) ejecting complex molecules to gas phase and a large amount of energy into the ISM. 


\subsection{The chemistry of complex molecules in the Galaxy}

The proposed gas-phase chemistry for some complex molecules does not seem to explain the similar abundances ratios observed in the GC clouds, in hot cores, and in hot corinos. From the empirical data gathered there, we can conclude that the most likely explanation for the large abundance of $\mathrm{CH}_{3} \mathrm{OH}, \mathrm{HCOOH}$, $\mathrm{HCOOCH}_{3},\left(\mathrm{CH}_{3}\right)_{2} \mathrm{O}$ and $\mathrm{C}_{2} \mathrm{H}_{5} \mathrm{OH}$ is that all these molecules are ejected from grains. It is interesting to note that in this scenario, the ice-mantle composition in complex organic molecules in the GC and in hot cores must be very similar. This is surprising in view of the changes of the complex organic molecules abundances observed in the hot corinos. The presence of complex molecules on grains can be due to grain chemistry or to the depletion after formation in gas phase.

Further investigations of the abundance of organic molecules in dark clouds are needed to constrain the molecules formed on ice mantles by grain chemistry in different types of molecular clouds.

\subsection{Sources with low $\mathrm{C}_{2} \mathrm{H}_{5} \mathrm{OH}$ abundances}

We also observed some clouds where the relative abundance of some organic complex molecules like $\mathrm{C}_{2} \mathrm{H}_{5} \mathrm{OH}$ seems to be significantly smaller than expected from these observed in other sources in the GC. These sources are the Sickle (MC G+0.18+0.04 and MC G+0.20+0.03) and the $-30 \mathrm{~km} \mathrm{~s}^{-1}$ velocity component of the TRA (MC G+0.13+0.02). We detected high $\mathrm{CH}_{3} \mathrm{OH}$ abundances of $\sim 10^{-7}$, but only significant upper limits, $\lesssim 0.4-5 \times 10^{-9}$ to the $\mathrm{C}_{2} \mathrm{H}_{5} \mathrm{OH}$ abundance. The stars from the Quintuplet and the Arches Clusters are said to heat and ionize the Sickle and the TRA (Rodríguez-Fernández et al. 2001b) creating photodissociation-regions (PDRs) around them. In particular, the $-30 \mathrm{~km} \mathrm{~s}^{-1}$ component is clearly associated with the TRA (Serabyn \& Güsten 1987).

The chemistry in these sources is then expected to be strongly affected by the presence of the UV radiation. It is very likely that the complex molecules in these sources are ejected to gas phase by shocks with the same abundances as observed in other GC molecular cloud. Additional evaporation from grain mantles can be ruled out since the heating will require UV photons that will also destroy the complex molecules. Due to a large UV radiation-field, the relative abundance of the complex molecules will be affected by dissociation. One can make a rough estimate of the effects of the UV radiation on the molecular abundances by comparing their photodissociation rates. Using the UMIST RATE99 (Le Teuff et al. 2000) and the Ohio State University databases ${ }^{1}$, we found that the photodissociation rates of $\left(\mathrm{CH}_{3}\right)_{2} \mathrm{O}$ and $\mathrm{C}_{2} \mathrm{H}_{5} \mathrm{OH}$ are larger than those of $\mathrm{CH}_{3} \mathrm{OH}, \mathrm{HCOOH}$ and $\mathrm{H}_{2} \mathrm{CO}$.

In Fig. 9 we show the results of a simple model in which we represent how the ejected complex organic molecules are photodestroyed as a function of time and visual extinction. The model considers a far-ultraviolet incident field $10^{3}$ times higher than in the local ISM $\left(G_{0}=10^{3}\right)$, which is the typical radiation field observed in GC PDRs (Rodríguez-Fernández et al. 2004). For the regions with low $A_{\mathrm{v}}$, all the abundances decrease, but the abundance of $\mathrm{C}_{2} \mathrm{H}_{5} \mathrm{OH}$ decreases faster than the other organic complex molecules. Obviously the time scale for photodissociation depends on the visual extinction. We estimate a visual extinction of $A_{\mathrm{v}} \sim 4-17 \mathrm{mag}$ for the Sickle and the TRA using our $\mathrm{H}_{2}$ column densities in Table 4 and the conversion factor given

\footnotetext{
${ }^{1}$ www.physics.ohio-state.edu/ eric/research.html
}
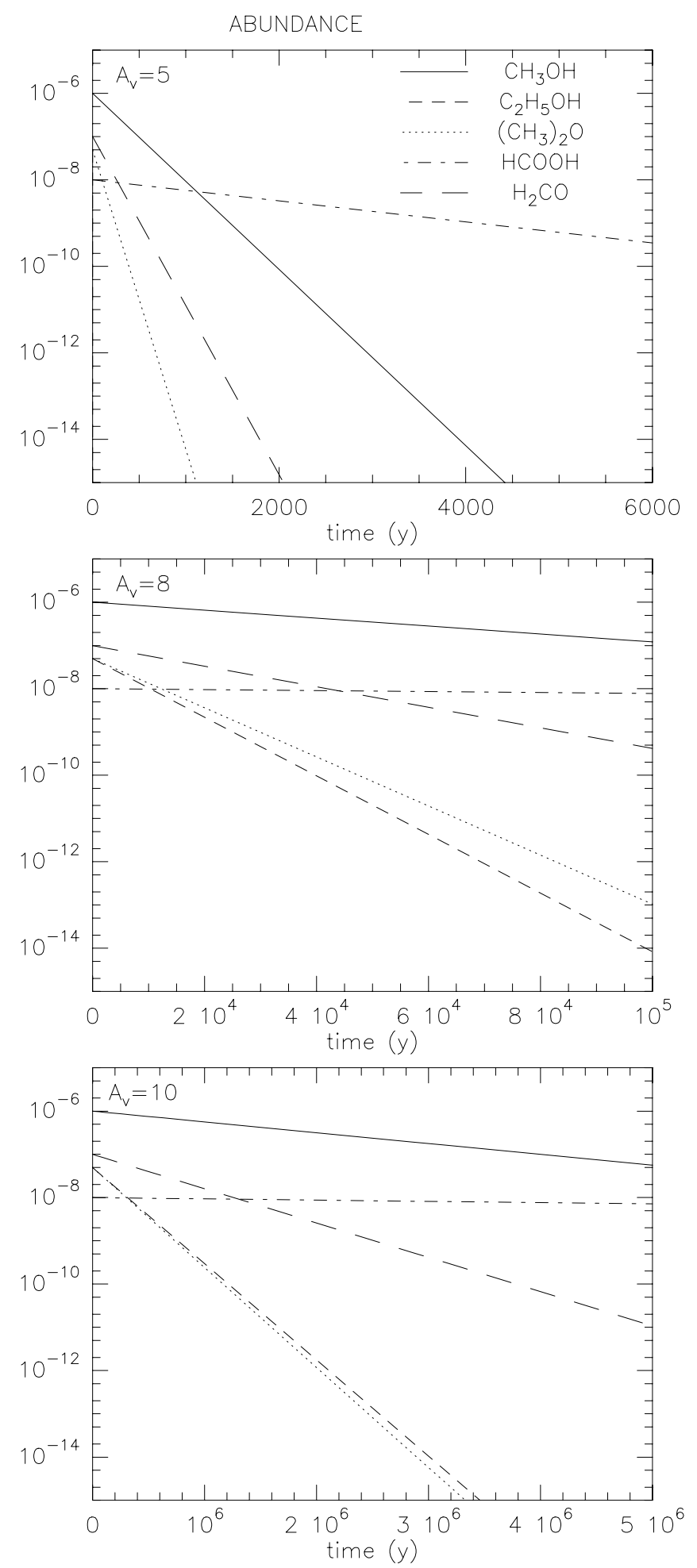

Fig. 9. Photodestruction of different complex molecules as a function of time for different visual extinctions $\left(A_{\mathrm{v}}\right)$. The initial molecular abundances for the molecules are considered to be those typically measured in the observed GC clouds. $G_{0}=10^{3}$, observed by Rodríguez-Fernández et al. (2004), is used for the UV radiation field.

by Bohlin $(1975), A_{\mathrm{v}}(\mathrm{mag})=10^{-21} \times N_{\mathrm{H}_{2}}\left(\mathrm{~cm}^{-2}\right)$. The photodissociation times scales for $\mathrm{CH}_{3} \mathrm{OH}$ will be comparable to depletion time scales for an averaged visual extinction of $\sim 8 \mathrm{mag}$.

For this visual extinction the other complex organic molecules will photodissociate much faster than the depletion 


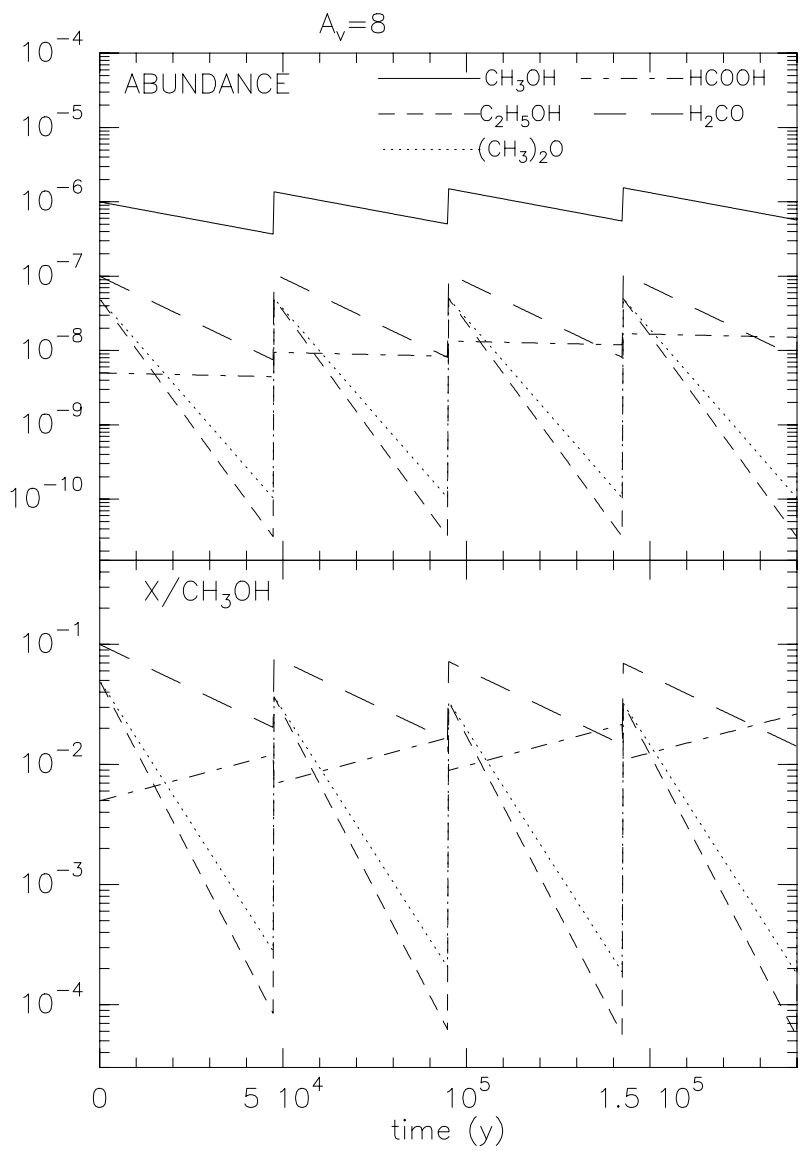

Fig. 10. Time evolution of the abundance (top) and relative abundance (bottom) of complex organic molecules with respect to that of $\mathrm{CH}_{3} \mathrm{OH}$ in a PDR with $A_{\mathrm{v}}=8 \mathrm{mag}$ where a periodic shock every $5 \times 10^{4}$ years enhances the abundances to their initial values. The radiation field is $G_{0}=10^{3}$.

time scale. This suggests that in the presence of UV radiation, large abundances of molecules like $\mathrm{C}_{2} \mathrm{H}_{5} \mathrm{OH}$ would require more frequent shocks than in the shielded regions. This is illustrated in Fig. 10, where we present the results of a simple model to show the time evolution of complex organic molecules in a region of $A_{\mathrm{v}}=8 \mathrm{mag}$. In this model, we consider the effects of the UV radiation on the complex molecules that have been ejected by periodic shocks of $5 \times 10^{4}$ years. They are ejected with the abundances measured in the GC and are destroyed because of the photodissociation. This simple model reproduces the constant high abundances observed for $\mathrm{CH}_{3} \mathrm{OH}$, while the abundances of $\mathrm{C}_{2} \mathrm{H}_{5} \mathrm{OH}$ can vary by $\sim 3$ orders of magnitude. In agreement with the observations, the photodissociation can reproduce the low abundances of $\mathrm{C}_{2} \mathrm{H}_{5} \mathrm{OH}$ in specific regions in the $\mathrm{GC}$ clouds. Further observation of complex organic molecules toward PDRs in the Galactic disk and in the Galactic center are required to test the proposed scenario.

\section{Conclusion}

We have found very high abundances for the complex organic molecules $\mathrm{CH}_{3} \mathrm{OH}, \mathrm{C}_{2} \mathrm{H}_{5} \mathrm{OH}, \mathrm{HCOOCH}_{3},\left(\mathrm{CH}_{3}\right)_{2} \mathrm{O}$, and $\mathrm{HCOOH}$ in the GC regions, similar to or even higher than those measured in Galactic hot cores. The abundance ratios of these molecules are fairly constant in all the GC clouds. The most likely explanation for these large abundances is that they have been ejected from grain mantles by shocks.
The highly turbulent molecular clouds in the GC could help to maintain the large gas phase abundance of complex molecules for time scales of $\sim 10^{5}$ years after the ejection by shocks. The rather uniform abundance ratios in clouds distributed over 200 pc indicate that the average composition of grain mantles is similar for all the GC clouds and also for the hot cores in the Galactic disk. We found that, in the GC PDRs, UV photons can differentially photodissociate the complex molecules, changing their relative abundances dramatically.

Acknowledgements. We wish to thank S. Bottinelli and her co-authors for communicating the results of their work prior to publication. This work was supported by the Spanish Ministerio de Educación y Ciencia under projects AYA 2002-10113-E, AYA 2003-02785-E, ESP 2004-00665 and "Comunidad de Madrid” government under PRICIT project S-0505/ESP-0277(ASTROCAM).

\section{References}

Aikawa, Y., Miyama, S. M., Nakano, T., \& Umebayashi, T. 1996, ApJ, 467, 684 Allen, M., \& Robinson, G. W. 1977, ApJ, 212, 396

Anderson, T., de Lucia, F., \& Herbst, E. 1990a, ApJ, 72, 797

Anderson, T., Herbst, E., \& de Lucia, F. C. 1990b, ApJ, 74, 647

Avila-Reese, V., \& Vázquez-Semadeni, E. 2001, ApJ, 553, 645

Bachiller, R., \& Pérez Gutiérrez, M. 1997, ApJ, 487, L93

Bohlin, R. C. 1975, ApJ, 200, 402

Bottinelli, S., Ceccarelli, C., Lefloch, B., et al. 2004a, ApJ, 615, 354

Bottinelli, S., Ceccarelli, C., Neri, R., et al. 2004b, ApJ, 617, L69

Bottinelli, S., Ceccarelli, C., Williams, J. P., \& Lefloch, B. 2006, A\&A, accepted Buch, V., \& Zhang, Q. 1991, ApJ, 379, 647

Caselli, P., Hasegawa, T. I., \& Herbst, E. 1993, ApJ, 408, 548

Cazaux, S., Tielens, A. G. G. M., Ceccarelli, C., et al. 2003, ApJ, 593, L51

Charnley, S. B., Dress, M. E., Tielens, A. G. G. M., \& Millar, T. J. 1995, ApJ, 448,232

Draine, B. T., \& Salpeter, E. E. 1979, ApJ, 231, 438

Dickens, J. E., Irvine, W. M., Snell, R. L., et al. 2000, ApJ, 54, 870

Elmegreen, B. G., \& Scalo, J. 2004, ARA\&A, 42, 211

Frerking, M. A., Langer, W. D., \& Wilson, R. W. 1982, ApJ, 262, 590

Gottlieb, C. A., Ball, J. A., Gottlieb, E. W., \& Dickinson, D. F. 1979, ApJ, 227, 422

Groner, P., Albert, S., Herbst, E., \& de Lucia, F. C. 1998, ApJ, 500, 1059

Güsten, R., \& Philipp, S. 2004 [arXiv: astro-ph/0402019]

Hasegawa, T. I., \& Herbst, E. 1993, MNRAS, 261, 83

Hasegawa, T., Sato, F., Whiteoak, J. B., \& Miyawaki, R. 1994, ApJ, 429, L77

Herbst, E., \& Leung, C. M. 1986, MNRAS, 222, 689

Herbst, E., \& Leung, C. M. 1989, ApJ, 69, 271

Horn, A., Mollendal, H., Sekiguchi, O., et al. 2004, ApJ, 611, 605

Hüttemeister 1993, Ph.D. Dissertation, Bonn University

Hüttemeister, S., Wilson, T. L., Bania, T. M., \& Martín-Pintado, J. 1993, A\&A, 280,255

Hüttemeister, S., Dahmen, G., Mauesberer, R., et al. 1998, A\&A, 334, 646

Ikeda, M., Ohishi, M., Nummelin, A., et al. 2001, ApJ, 560, 792

Jiménez-Serra, I., Martín-Pintado, J., \& Rodríguez-Franco, A. 2005, ApJ, 627, L121

Johnson, D. R., Lovas, F., \& Kirchhoff, W. H. 1972, J. Phys. Chem. Ref. Data, 1,1972

Jørgensen, J. K., Schöier, F. L., \& van Dishoeck, E. F. 2005, A\&A, 437, 501

Kaufman, M. J., \& Neufeld, D. A. 1996, ApJ, 456, 611

Kuan, Y.-J., \& Snyder, L. E. 1996, ApJ, 470, 981

Kuan, Y.-J., Huang, H.-C., Charnley, S. B., et al. 2004, ApJ, 616, L27

Le Teuff, Y. H., Millar, T. J., \& Markwick, A. J. 2000, A\&AS, 146, 157

Leitch-Devlin, M. A., \& Williams, D. A. 1985, MNRAS, 213, 295

Leung, C. M., Herbst, E., \& Huebner, W. F. 1984, ApJS, 56, 231

Liu, S.-Y., Girart, J. M., Remijan, A. J., \& Snyder, L. E. 2002, ApJ, 576, 255

Mac Low, M.-M., Dlessen, R. S., Burkert, A., \& Smith, M. D. 1998, Phys. Rev. Lett., 80, 2754

Maret, S., Ceccarelli, C., Caux, E., et al. 2004, A\&A, 416, 577

Martín, et al. 2006, in preparation

Martín-Pintado, J., de Vicente, P., Fuente, A., \& Planesas, P. 1997, ApJ, 482, L45

Martín-Pintado, J., Gaume, R. A., Rodríguez-Fernández, N. J., de Vicente, P., \& Wilson, T. L. 1999, ApJ, 519, 667

Martín-Pintado, J., Rizzo, J. R., de Vicente, P., Rodríguez-Fernández, N. J., \& Fuente, A. 2001, ApJ, 548, L65

Masuda, K., Tkahashi, J., \& Mukai, T. 1998, A\&A, 330, 773

Mehringer, D. M., Snyder, L. E., \& Miao, Y. 1997, ApJ, 480, L71

Menten, K. M., Walmsley, C. M., Henkel, C., \& Wilson, T. L. 1986, A\&A, 157, 318 
Millar, T. J., Herbst, E., \& Charnley, S. B. 1991, ApJ, 369, 147

Minh, Y. C., Irvine, W. M., \& Friberg, P. 1992, A\&A, 258, 489

Morris, M., \& Serabyn, E. 1996, ARA\&A, 34, 645

Pearson, J. C., Sastry, K. V. L. N., Winnewisser, M., Herbst, E., \& de Lucia, F. C. 1995, J. Phys. Chem. Ref. Data, 24, 1

Pearson, J. C., Sastry, K. V. L. N., Herbst, E., \& de Lucia, F. C. 1997, ApJ, 480, 420

Peeters, Z., Rodgers, S. D., Charnley, S. et al. 2006, A\&A, 445, 197

Plummer, G. M., Herbst, E., de Lucia, F. C., \& Blake, G. A. 1984, ApJ, 55, 633

Plummer, G. M., Herbst, E., de Lucia, F. C., \& Blake, G. A. 1986, ApJ, 60, 949

Pottage, J. T., Flower, D. R., \& Davis, S. L. 2004, MNRAS, 352, 39

Remijan, A., Snyder, L. E., Liu, S.-Y., Mehringer, D. M., \& Kuan, Y.-J. 2002, ApJ, 576, 264

Remijan, A., Snyder, L. E., Friedel, D. N., Liu, S.-Y., \& Shah, R.-Y. 2003, ApJ, 590,314

Rodgers, S. D., \& Charnley, S. B. 2001, ApJ, 546, 324

Rodríguez-Fernández, N. J., \& Martín-Pintado, J. 2005, A\&A, 429, 923

Rodríguez-Fernández, N. J., Martín-Pintado, J., de Vicente, P., et al. 2000, A\&A, 356,695
Rodríguez-Fernández, N. J., Martín-Pintado, J., Fuente, A., et al. 2001a, A\&A, 365,174

Rodríguez-Fernández, N. J., Martín-Pintado, J., \& de Vicente, P. 2001b, A\&A, 377,631

Rodríguez-Fernández, N. J., Martín-Pintado, J., Fuente, A., \& Wilson, T. L. 2004, A\&A, 427, 217

Rodríguez-Fernández, N. J., Combes, F., Martín-Pintado, J., Wilson, T. L., \& Apponi, A. 2006, A\&A, accepted [arXiv: astro-ph/0603851]

Serabyn, E., \& Güsten, R. 1987, A\&A, 184, 133

Serabyn, E., \& Güsten, R. 1991, A\&A, 242, 376

Smith, M. D., Mac Low, M.-M., \& Zuev, J. M. 2000, A\&A, 356, 287

Stone, J. M., Ostriker, E. O., \& Gammie, C. F. 1998, ApJ, 508, L99

Tielens, A. G. G. M., \& Hagen, W. 1982, A\&A, 114, 245

Turner, B. E., Terziava, R., \& Herbst, E. 1999, ApJ, 518, 699

Turner, B. E. 2000, ApJ, 542, 837

Willemot, E., Dangoisse, D., Monnanteuil, N., \& Bellet, J. 1980, JPCRD, 9, 59

Wilson, T. L., \& Rood, R. T. 1994, ARAA, 32, 191

Wlodarczad, G., \& Demaison, J. 1988, A\&A, 192, 313

Xu, L.-H., \& Lovas, F. L. 1997, JPCRD, 26, 17 